\title{
Quantifying Fractal Dimension in Integrated Experimental Data of Tight Sandstones
}

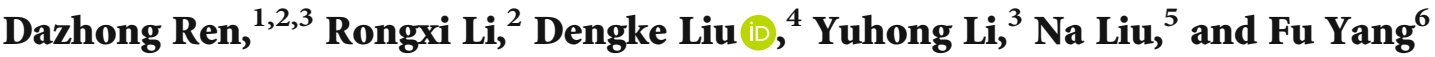 \\ ${ }^{1}$ Shaanxi Key Laboratory of Advanced Stimulation Technology for Oil \& Gas Reservoirs, Xi'an Shiyou University, \\ Xi'an 710065, China \\ ${ }^{2}$ School of Earth Science and Resources, Chang'an University, Xi'an 710054, China \\ ${ }^{3}$ Xi'an Geological Survey Center, China Geological Survey, Xi'an 710054, China \\ ${ }^{4}$ School of Human Settlements and Civil Engineering, Xi'an Jiaotong University, Xi'an 710054, China \\ ${ }^{5}$ PetroChina Research Institute of Petroleum Exploration \& Development, Beijing 100083, China \\ ${ }^{6}$ Key Laboratory of Coal Resources Exploration and Comprehensive Utilization, Ministry of Land and Resources, \\ Xi'an 710021, China
}

Correspondence should be addressed to Dengke Liu; liudengke02@126.com

Received 10 June 2019; Accepted 12 August 2019; Published 5 November 2019

Academic Editor: Stefano Lo Russo

Copyright (C) 2019 Dazhong Ren et al. This is an open access article distributed under the Creative Commons Attribution License, which permits unrestricted use, distribution, and reproduction in any medium, provided the original work is properly cited.

Determining the microscopic pore structures of tight sandstones is becoming one of the most challenging efforts, and the strong heterogeneity makes the accurate assessment still a problem. In this research, we report a new criterion for pore structure typing based on the fractal geometry theory. The fractal dimension values were first accurately calculated through intrusion and nonintrusion methods. The results show that the pores in tight sandstones have multifractal distributions and different types of pore structure were divided based on various tests. The relationships between petrophysical properties and a series of multifractal parameters have been analyzed in detail. The fractal dimension values of type 1 sandstones derived from the throat curves in rate-controlled mercury intrusion methods can well characterize the porosity of the research area, while the others did not respond well. Finally, a multifractal criterion was proposed to analyze the petrological and pore structures by combined observations and experiments. The new criterion exhibits perfect performance in the prediction of the storage capacity. The multifractal model proposed in this research helps to assess the pore structures of tight sandstones and helps to characterize the reservoir quality in hydrocarbon exploration and development.

\section{Introduction}

In view of the serious shortage of energy supply, tight sandstones have drawn much attention due to their considerable exploration and exploitation potential [1,2]. Expressing quantitatively the pore structures of tight sandstones, including heterogeneities of pore geometries, pore connectivity, and pore size distributions is becoming one of the most important works because an accurate description of pore structures is conducive to evaluating both storage capacities and percolation properties [3-5]. As complex geological materials, tight sandstones are dominated by nano- to millimeter-scale pores, making the characterization of the pore structure significantly different from those of conventional sandstones, and these sandstones have been paid much attention by the researchers [6-8]. However, the pore systems in tight sandstones are extremely complex, so the geoscientists have inadequate knowledge of the microscopic pore structures and this lack of knowledge has resulted in many intractable issues that remain to be resolved [9]. Several research has deciphered that the pore size distributions of tight sandstones could be approximated by a fractal scaling, in which the number of pores whose sizes are greater than the pore radius $r$ could be written as $N(>r) \propto a r^{-D}$ and $D$ is the fractal dimension [10-13]. There has been a growing enthusiasm in employing fractals for comprehending the pore structures of tight formations. The fractal theory offers a successful prediction of the geometric morphology of porous media, builds up 
the relationships between microscopic pore system heterogeneities and macroscopic spatial qualities in sediments, and governs rules that simplify complex characteristics in nature $[4,14]$. By determining the fractal distributions of the tight sandstones, the topology of the pore space could be analyzed [15], the pore volume of different porous media can be quantitatively characterized [16, 17], and the fractal dimensions of pore structures can also be used to relate the pore-scale understanding of the pore systems to core-scale measurements, such as porosity and permeability $[4,11]$.

Calculation of fractal dimensions might be accomplished by analysis of microscopic images (such as thin sections (TS) [18] and scanning electron microscopy (SEM) [15]), measurements of capillary pressure (including pressurecontrolled mercury intrusion (PCMI) [19] and ratecontrolled mercury intrusion (RCMI) [20]), or water retention (e.g., nuclear magnetic resonance (NMR) [21]). Because the use of microscopic images requires a tradeoff between representativeness and distinguishability $[9,22]$, in general, the indirect methods have been conducted to calculate the fractal dimensions [19-21]. The fractal distributions can only be partially revealed using any of the sole experiment because each method has its only limitations and strengths. PCMI may be used to detect the tiny pores $(<2 \mu \mathrm{m})$ (corresponding to high fractal dimensions) but affected by the pore shielding effect which leads to the limitations in computing the large pores $[23,24]$. RCMI can distinguish pores from throats and provide their respective fractal dimensions $[25,26]$; however, because of the limited maximum intrusion pressure, the tiny pores cannot be comprehensively detected [27]. NMR measurements offer a nondestructive and time-saving alternative to calculate fractal dimensions; nevertheless, this tool cannot probe signals from very small pores due to the scarcity of relatively lower echo spacing [28, 29]. A more integrated and sophisticated method must, therefore, be used to combine PCMI, RCMI, and NMR data to acquire the accurate fractal distributions.

The major aims of this paper are to derive fractal models from hybrid techniques, including PCMI, RCMI, and NMR and to reveal the fractal features of Permian tight sandstones from the Ordos Basin of northwest China. Additionally, multiscale imaging from TS and SEM was performed to characterize pore geometry and X-ray diffraction (XRD) methods were conducted to analyze the mineral features and contents quantitatively. Then, by considering the multifractal distributions instead of the singular fractal dimension value, a new criterion of the reservoir type is developed based on the fractal assumptions of pores to characterize the petrophysical property-mineralogical assembly-pore structure relationship for evaluating the pore structure typing and reservoir quality. Finally, through a series of comparisons, the most effective fractal dimension values for estimating the reservoir quality of tight sandstone have been proposed. In conclusions, the main goal of this research is to propose a new criterion to more accurately classify the reservoir quality and study the differences of the petrology and pore structures of each pore structure typing.

\section{Materials and Methods}

2.1. Geological Setting. The Ordos Basin, located in the northwest of China with an area of 37.104 million $\mathrm{km}^{2}$ (14.326 million $\mathrm{mi}^{2}$ ), is the second largest sedimentary basin in China (Figure 1(a)) [2]. The margins of the basin experienced intense tectonic movements, while the interior basin, in areas where the rigid basement was developed, is characterized by deficient faults and folds and the strata slightly tilted to the west with a dip of less than $1^{\circ}[4$, 27]. The Ordos Basin is tectonically bound by the Yimeng Uplift to the north, the Weibei Uplift to the south, the Xiyuan Thrust Belt to the west, and the Jinxi Fault-Fold Belt to the east. Among them, the Yishan Slope and Yimeng Uplift are located to the northern of the Ordos Basin and they are the main area of gas development in the basin (Figure 1(a)). The Shihezi Formation, which can be subdivided into 8 members, is one of the major pay zones of the Ordos Basin, which belong to the lacustrine deltaic and fluvial sedimentary system with a thickness of 200-300 m (656-984ft) (Figure 1(b)) [30, 31].

2.2. Experimental Measurements. In this research, 41 tight sandstone specimens were collected by sealing core drilling from the Shihezi Formation. The specimens were all regular cylinders drilled from a homogeneous section perpendicular to the bedding with around $5.5 \mathrm{~cm}$ in length and $2.54 \mathrm{~cm}$ in diameter. After removing the residual bitumen by submerging into a mixture of alcohol and chloroform then dried at $130^{\circ} \mathrm{C}$ for $24 \mathrm{~h}$, helium porosity and nitrogen permeability of specimens were tested using the FYK-I apparatus under the confine stress of $20 \mathrm{MPa}$, following the standard SY/T 6385-2016 of China [32] and specimens were subsequently cut into six parts for TS, SEM, XRD, PCMI, RCMI, and NMR tests.

For the thin section, the specimens were pumped under vacuum first and then the pores were impregnated with red epoxy resin. Finally, they were ground to approximately $0.03 \mathrm{~mm}$ in thickness and the Zeiss Axioskop II microscope was used to observe the pore systems and petrological features. In the process of SEM sample making, the polished sections and freshly fractured specimens were coated with gold first and the spatial distribution of minerals and pore structures was analyzed using FEI Quanta 400 FEG SEM with an accelerating voltage of $20 \mathrm{kV}$. Detailed steps of thin sections and SEM followed the standards SY/T 5368-2016 [33] and SY/T 5162-2014 of China [34], respectively.

Before clay fraction XRD experiment, the specimens were crushed into approximately 200 mesh $(75 \mu \mathrm{m})$ first and then the powder specimens were mixed with ethanol and subjected to heating at $55^{\circ} \mathrm{C}$ in a water bath to remove carbonate. Clay fraction was separated by evaporation and laid on glass slides. The test was performed at a temperature of $24^{\circ} \mathrm{C}$ and humidity of $30 \%$ using X'Pert PRO energy dispersive X-ray spectrometer; all specimens were measured at $40 \mathrm{kV}$, $40 \mathrm{~mA}$, with a $0.02^{\circ}$ step size and scanning speed of $2^{\circ} / \mathrm{min}$. The quantitative analysis of clay fraction composition was carried out according to the standard SY/T 5163-2010 of China [35]. 


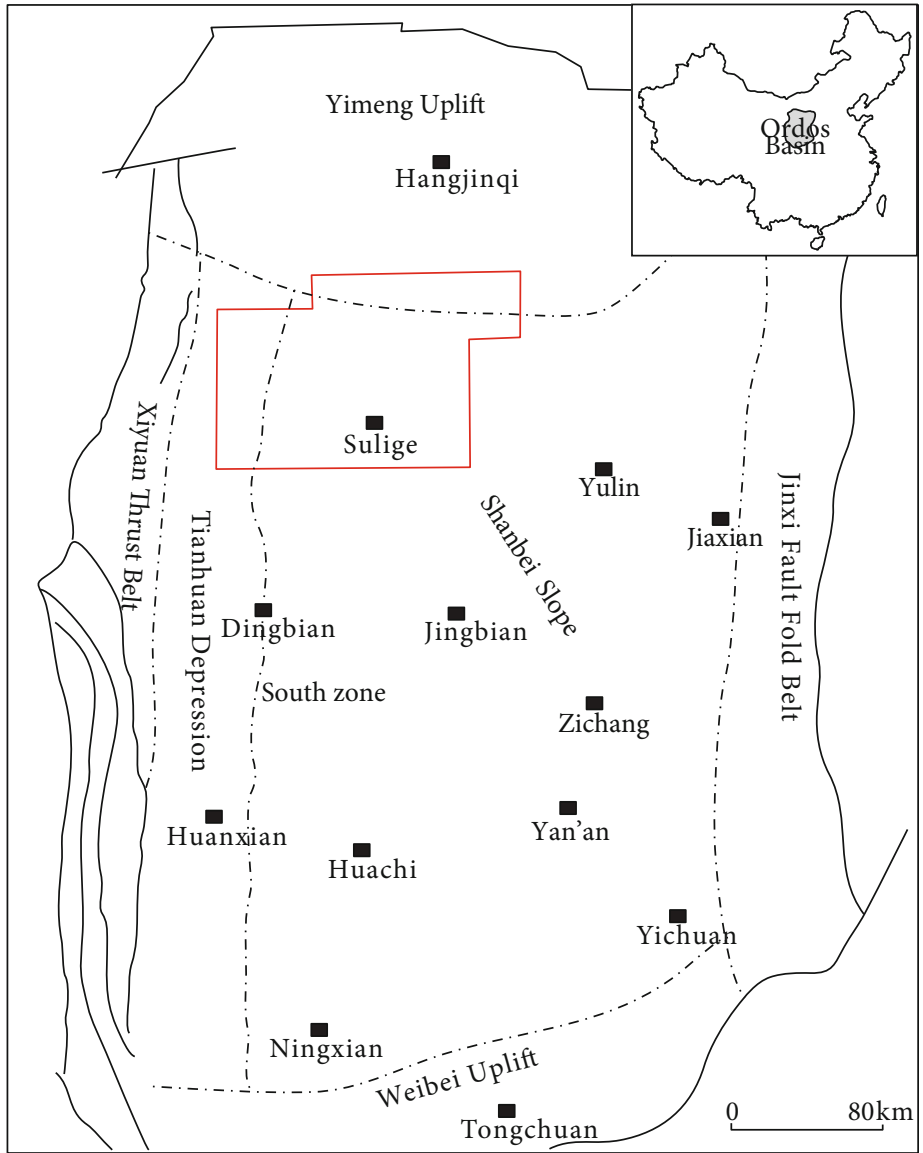

$\square$ Sample location

- Boundary of first-class tectonic unit

$\square$ Boundary of the basin

\begin{tabular}{|c|c|c|c|c|}
\hline System & Series & Formation & Thickness & $\begin{array}{c}\text { Lithology } \\
\text { profile }\end{array}$ \\
\hline Triassic & Lower & Liujiagou & $202-422$ & 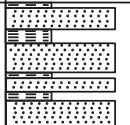 \\
\hline \multirow{4}{*}{ Permian } & \multirow{2}{*}{ Upper } & Shiqianfeng & $200-345$ & 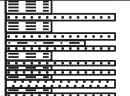 \\
\hline & & $\begin{array}{l}\text { Upper } \\
\text { Shihezi }\end{array}$ & $130-160$ & 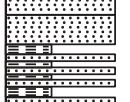 \\
\hline & \multirow{2}{*}{ Lower } & $\begin{array}{l}\text { Lower } \\
\text { Shihezi }\end{array}$ & $140-160$ & 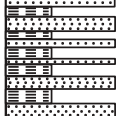 \\
\hline & & Shanxi & $90-120$ & 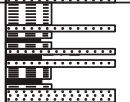 \\
\hline \multirow{2}{*}{ Carboniferous } & Upper & Taiyuan & $60-80$ & 7tmin \\
\hline & Middle & Benxi & $10-40$ & 要 \\
\hline \multirow{5}{*}{ Ordovician } & Upper & Beiguoshan & $0-330$ & 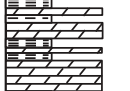 \\
\hline & Middle & Pingliang & $130-480$ & 产 \\
\hline & \multirow{3}{*}{ Lower } & Majiagou & $400-600$ & 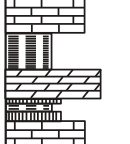 \\
\hline & & Liangjiashan & $100-200$ & 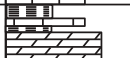 \\
\hline & & Yeli & $60-170$ & 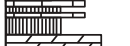 \\
\hline
\end{tabular}

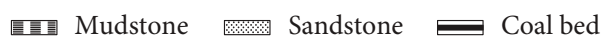
Limestone Dolomite Gypum

(b)

(a)

Figure 1: (a) Locations of the Ordos Basin and the tectonic divisions of the Ordos Basin and (b) comprehensive Ordovician MajiagouTriassic Liujiagou stratigraphic column of the Ordos Basin $[2,4,27,31]$.

Since the PCMI and RCMI are destructive testing, NMR experiments were preferentially performed on all specimens by the Niumag NMR apparatus at a proton resonance frequency of $2 \mathrm{MHz}$ and detected by a CPMG pulse sequence [36]. Before the specimens were put into the apparatus, they were fully saturated in $25000 \mathrm{mg} / \mathrm{L}$ $\mathrm{CaCl}_{2}$ brine solution, consistent with the formation water to prevent the clay minerals from swelling, for $12 \mathrm{~h}$ under a vacuum state. Based on the standard SY/T 6490-2014 of China [37], the experimental parameters were selected as follows: echo numbers, 6000; echo spacing, $100 \mu \mathrm{s}$; number of scans, 64; waiting time, $5 \mathrm{~s}$; and TE, $0.3 \mathrm{~s}$. After the NMR tests, all specimens were washed, dried, and then split into two pieces for the PCMI and RCMI tests.

In this research, the specimens were installed in a Micromeritic AutoPore IV 9420 and an ASPE 730 mercury porosimeter to acquire the PCMI and RCMI data, respectively. In the PCMI analysis, a progressive increment of the intrusion pressure was accompanied by a progressive increment of nonwetting phase injection inside the pore spaces and the instrument generates pressure as high as $200 \mathrm{MPa}$ (29008 psi) for pore size distribution (PSD) analysis in the pore radius range of $168 \mu \mathrm{m}-0.004 \mu \mathrm{m}$ according to the Washburn equation [38] and the results reported by Purcell [39]. All experimental steps referred to the standard SY/T 5346-2005 of China [40]. In the process of RCMI experiments, the intrusion pressure is controlled below 6.2 MPa (900 psi) (corresponding to $0.12 \mu \mathrm{m}$ according to the Washburn equation [38] and the results reported by Purcell [39]) in order to keep the constant rate of mercury intrusion $(0.00005 \mathrm{~mL} / \mathrm{min})$. The details of pores and throats can be distinguished by the detection of pressure fluctuation [25].

2.3. Fractal Analysis Theory. Fractal dimensions can quantitatively describe the pore-throat systems by comparing the structure irregularity and surface complexity in tight 
sandstones, which have been considered to have a fractal property [20,41, 42]. Based on the fractal theory, the counted $N(>r)$, which is corresponding to the pores and throats with a radius over $r$, can be expressed as follows [43]:

$$
N(>r)=\int_{r}^{r_{\max }} P(r) d r=a r^{-D},
$$

where $r_{\max }$ is the maximum value of the pore radius, in $\mu \mathrm{m}$, $P(r)$ refers to a density function of the pore radius, $a$ is a dimensionless constant, and $D$ represents the fractal dimension. Generally, $D$ is ranging from 2.0 to 3.0 in threedimensional spaces and the greater the fractal dimension, the greater the heterogeneity $[44,45]$.

2.3.1. Intrusion Method-Based Fractal Dimensions. According to equation (1), the following equation can be obtained by derivation with respect to $r$ :

$$
P(r)=\frac{d N(>r)}{d r}=b r^{-D-1}
$$

where $b$ is a dimensionless constant equal to $-D \times a$.

Thus, the cumulative pore volume with radius over $r$ $[V(>r)]$ can be calculated as follows:

$$
V(>r)=\int_{r}^{r_{\max }} P(r) \pi \alpha d r
$$

where $\alpha$ is relevant to void space morphology; if it simplifies pores as the cylinder, $\alpha=r^{2} l$, where $l$ represents the length of the cylinder; and if the sphere model is used for pores, $\alpha$ equals to $4 r^{3} / 3$.

The pore morphology is equivalent to that of the cube; thus, by setting $\alpha$ to be equal to $r^{2} l$ and assuming that $l$ is equal to $r$ in this case as a tubular bundle model [12, 46], one can obtain

$$
V(>r)=\int_{l}^{l_{\max }} \int_{r}^{r_{\max }} P(r) \pi r^{2} l d r=\int_{r}^{r_{\max }} P(r) \pi r^{3} d r .
$$

Substituting equation (2) into equation (4), $V(>r)$ can be expressed as follows:

$$
V(>r)=c\left(r_{\max }^{3-D}-r^{3-D}\right)
$$

where $c$ refers to a dimensionless constant and equals to $a b /$ $3-D$. Similarly, the total pore volume can be obtained.

$$
V=c\left(r_{\max }^{3-D}-r_{\min }^{3-D}\right)
$$

where $r_{\max }$ is the minimum value of the pore radius, in $\mu \mathrm{m}$. Based on equation (6), the fractal dimensions of the pore structure from the intrusion method, defined here as the PCMI and RCMI tests, can be calculated [4, 12, 47]. Mercury is the nonwetting phase in the process of intrusion; hence, the mercury intrusion saturation with a pore radius larger than $r$ in $\%\left(S_{H g}(>r)\right)$ can be obtained.

$$
1-S_{H g}(>r)=\frac{V(<r)}{V}=\frac{r^{3-D}-r_{\min }^{3-D}}{r_{\max }^{3-D}-r_{\min }^{3-D}} .
$$

The pore space of sandstones is self-similar over 3 to 4 orders of magnitude in length extending from $10 \AA$ to over $100 \mu \mathrm{m}$ [15], indicating that the value of the minimum pore radius is far below the maximum one; equation (7) can then be written as

$$
\begin{aligned}
1-S_{H g}(>r) & =\frac{r^{3-D}-r_{\min }^{3-D}}{r_{\max }^{3-D}} \\
& =\left(\frac{r}{r_{\max }}\right)^{3-D}-\left(\frac{r_{\min }}{r_{\max }}\right)^{3-D} \\
& =\left(\frac{r}{r_{\max }}\right)^{3-D} .
\end{aligned}
$$

The capillary pressure $\left(P_{c}\right)$ is inversely proportional to the pore radius according to the Washburn equation [38]; then equation (8) is changed as follows:

$$
1-S_{H g}(>r)=\left(P_{c}-P_{\min }\right)^{D-3},
$$

where $P_{\min }$ represents the capillary pressure corresponding to the maximum pore radius; taking a logarithm on the above formula, the derivative of equation (9) is calculated as

$$
\lg \left(1-S_{H g}(>r)\right)=(D-3) \lg P_{c}-(D-3) \lg P_{\min } .
$$

It demonstrates that $\lg \left(1-S_{H g}(>r)\right)$ is linearly proportional to $\lg P_{c}$ and the value could be determined according to the experimental data by PCMI and RCMI tests; then the slope of the linear correlation between $\lg \left(1-S_{H g}(>r)\right)$ and $\lg P_{c}(k)$ can be determined:

$$
\begin{aligned}
& D-3=k, \\
& D=k+3 .
\end{aligned}
$$

The intrusion and extrusion curves of PCMI and the throats and pore branches from RCMI tests can be separated into some segments to represent fractal dimensions of different sizes and forms of pores and throats. Based on this theory, the fractal dimensions of different pore-throat characteristics can be determined.

2.3.2. Nonintrusion Method-Based Fractal Dimensions. As a typical nonintrusion method, NMR data could be described by the fractal model [4]. It is generally assumed that the NMR $T_{2}$ relaxation time could be related directly to the pore radius $[48,49]$. Assuming that the magnetic field gradient was constant and equal in all pores, the $T_{2}$ relaxation time is a function of the pore radius:

$$
\frac{1}{T_{2}}=\rho \frac{C}{r}=\rho \frac{2}{r},
$$


where $T_{2}$ is the relaxation time; the constants of proportionality $(\rho)$ are the surface relaxivities; we assumed the pore shapes to be cylinders; thus, $C$ is equal to 2 [11]. From equation (12), it could be concluded that shorter relaxation time is associated with small pores, whereas $T_{2}$ relaxation time of large pores is long [50].

The signal amplitude at each time constant is a function of the pore volume corresponding to the pore radius [51], and the total volume of the pores $\left(V_{p}\right)$ is the sum of the signal amplitudes from the minimum to maximum $T_{2}$ values, namely,

$$
V_{p}=\sum_{i=1}^{n} V_{p i}
$$

where $V_{p i}$ is corresponding to pore radius $r_{i}$, the pore volume therefore is associated with the $T_{2}$ relaxation time; thus, combining equations (12) and (13), the number of pores (tubular bundle model) of a given radius is given by

$$
N_{i}=\frac{V_{p i}}{\pi r_{i}^{3}}=\frac{V_{p i}}{8 \pi\left(\rho T_{2 i}\right)^{3}} .
$$

Hence, the pore numbers composed of the pore radius larger than $r_{i}$ are expressed in

$$
N(>r)=\sum_{i+1}^{n} N_{i+1}
$$

Equation (16) can be obtained by combining equations (1), (12), (14), and (15):

$$
N(>r)=\sum_{i+1}^{n} \frac{V_{p(i+1)}}{8 \pi\left(\rho T_{2(i+1)}\right)^{3}}=a\left(2 \rho T_{2 i}\right)^{-D} .
$$

Taking a logarithm on the above formula, the derivative of equation (16) is calculated as

$$
\lg \left(\sum_{i+1}^{n} \frac{V_{p(i+\mathrm{i})}}{\left(\rho T_{2(i+1)}\right)^{3}}\right)+\lg \frac{1}{8 \pi \rho^{3}}=\lg a-D \lg (2 \rho)-D \lg \left(T_{2 i}\right),
$$

where $\lg \left(1 / 8 \pi \rho^{3}\right), \lg a$, and $\lg (2 \rho)$ are constant. In the NMR tests, the signal amplitude can represent the pore volume [4], so the fractal dimension could be derived from the slope of the best fit line on the double logarithmic plot $(\lg (N(>r))$ $\left.-\lg \left(T_{2 i}\right)\right)$ equation (17).

\section{Results}

3.1. Petrological Characteristics, Petrophysical Properties, and Pore Types. For the gas layer (reservoir), the lithology of the $\mathrm{H} 8$ member is mainly of litharenite and sublitharenite, with quartz accounting for $67.62 \%$, feldspar $0.15 \%$, rock fragments $14.00 \%$, and interstitial materials $18.23 \%$, revealing that the mineral composition is highly heterogeneous and dominated by quartz (Figure 2(a)). Clay mineral contents range from $1.53 \%$ to $10.56 \%$, with an average of $5.67 \%$. Kaolinite is the most clay mineral species (av. 46.96\%), followed by illite (av. 25.45\%), chlorite (av. 20.80\%), and mixed-layer illite/smectite (I/S) (6.78\%) (Figure 2(b)). No pure smectite was found in the specimens. The content of carbonate is highly variable, ranging from zero to $38.20 \%$ with an average of $2.70 \%$ (Figure $2(\mathrm{c})$ ). The calcite group mineral (calcite and ferrocalcite (Fe-calcite)) is the dominant carbonate mineral in the $\mathrm{H} 8$ tight sandstones, with an average content of $82.87 \%$ (Figure 2(c)). The content of the dolomite group mineral (dolomite and ankerite (Fe-dolomite)) is relatively low, with an average content of $7.28 \%$. Another type of carbonate is $9.84 \%$ (Figure $2(\mathrm{c})$ ).

The porosities of the $\mathrm{H} 8$ tight sandstones ranged from $4.02 \%$ to $16.85 \%$ with an average of $10.25 \%$, and the air permeability ranged from 0.002 to $5.609 \mathrm{mD}$ with an average of $0.583 \mathrm{mD}$. The pores in the $\mathrm{H} 8$ tight sandstones could be divided into three types based on the direct observation of the pore morphology by TS and SEM: intergranular pores, dissolution pores, and interstitial mineral-related pores. The intergranular pores can be subdivided into two groups: original intergranular pores and residual intergranular pores. Due to the intensive diagenesis in the H8 tight sandstones, the original intergranular pores were vanished [52]; instead, the residual intergranular pores are very large in size (mainly $>10 \mu \mathrm{m}$ ) and they are the dominant pore types. In Figure 3(a), good petrophysical property sandstones are mainly supported by coarse, well-sorted grains and comprised ample intergranular pores. The dissolution pores contained two subtypes, including interparticle dissolution pores and interparticle dissolution pores (Figures 3(b) and 3(c)). Although dissolution pores can result in more pore spaces, they make little contribution to permeability unless they are interconnected. The pores associated with interstitial minerals mainly resulted from the diagenetic alteration [53]. In the H8 tight sandstones, illite, chlorite, kaolinite, and the I/S mixed layer provide many intercrystalline pores with a smaller pore radius (Figures 3(d)-3(f)), thereby increasing the complexity of the pore network and deteriorating the petrophysical properties.

\subsection{Pore Size Fractal Dimension}

3.2.1. Fractal Dimensions from PCMI. All pore fractal dimension values $D$ from the PCMI, RCMI, and NMR tests were calculated by the algorithm mentioned above. For most of the tests, good and straight regression lines with $R^{2}$ greater than 0.9 were observed, indicating that the pore structures of these specimens were virtually fractal. Due to the sedimentary background differences and the influence of post sedimentary alteration, tight sandstones are typically characterized by intricate pore geometry [54]; therefore, for the selected tight sandstone specimens, there are significant discrepancies between different specimens. We divided the intrusion curves into two different types, and four typical specimens were chosen to obtain double logarithmic curves (Figures 4(a) 


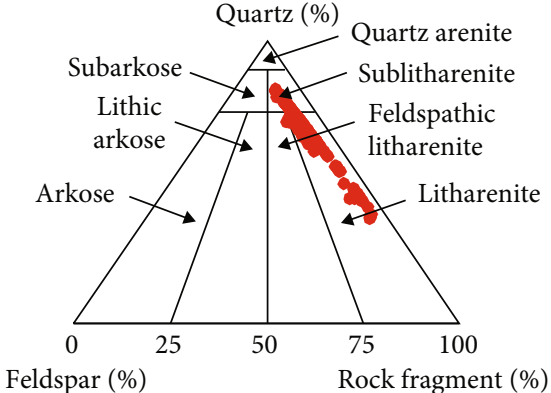

(a)

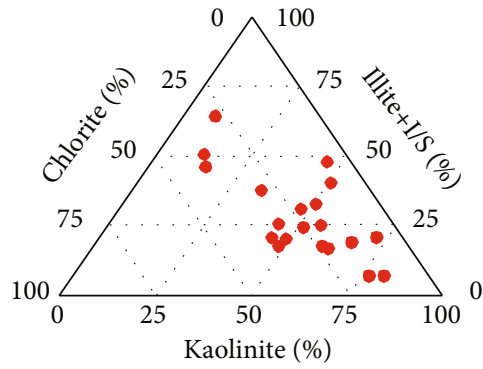

(b)

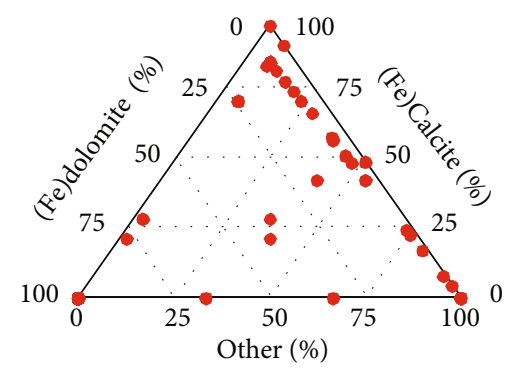

(c)

Figure 2: Ternary diagrams of the (a) detrital grain content, (b) bulk clay composition, and (c) bulk carbonate constitution of H8 tight sandstones.

and 4(b)). Each type reflects a specific pore geometry. The specimens from J25, S79, and S92 exhibited type I intrusion-related PSDs. The intrusion branches change slowly, and the all the pores are defined as self-similar objects with a unique fractal dimension (Figure 4(a)). For the type II intrusion-related PSDs, the plot of the PCMI test can be divided into two segments and the inflection point is the boundary of large and small fractal pore sets (Figure 4(b)). The slope for the larger pores is relatively gentle, corresponding to a high fractal dimension value, whereas the slope for the smaller pores is steep, corresponding to a relatively low fractal dimension value, revealing considerable discrepancies between the smaller and larger pores (Figure 4(b)). The extrusion branches of type I also have similar features, whereas the analyses of the mercury extrusion curve show that the fractal dimension of interconnected pores is generally large, suggesting that this kind of pores has a major implication in terms of pore structure heterogeneity (Figure 4(c)) [23]. Meanwhile, the extrusion curve of type II is inhomogeneity compared with that of type I (Figures 4(b) and 4(d)). By mixing and matching different types of intrusion and extrusion curves, the demanding needs of fractal feature evaluation were met.

3.2.2. Fractal Dimensions from RCMI. Similar phenomena are found in RCMI-derived plots, in which the fractal distribution is presented in Figure 5, and the plots of throats and pores can be grouped into two and three types, respectively. For the type I throat type, the throat set of three typical specimens was roughly in line with each other with a unique fractal dimension (Figure 5(a)). In the type II throat type, however, the slope for the smaller throats is relatively steep, corresponding to low fractal dimension, whereas the slope for the large throats is relatively gentle, corresponding to low fractal dimension (Figure 5(b)). The RCMI-derived pores could be divided into three parts; the trends of types I and II share similar trends with that of the throat set, while in some specimens, a ternary pattern was observed and the dimension values are creeping higher from large small pores, corresponding to the type III pore set (Figures 5(c)-5(e)). Like the results of PCMI tests, we use variations of the throat set, which are selected to suit each individual pore set.

3.2.3. Fractal Dimensions from NMR. In Figure 6(a), $\lg \left(T_{2}\right)$ was plotted against $\lg (N(>r))$ for specimens S27, S31, and S92 and good, straight regression lines with an $R^{2}$ greater than 0.96 are observed, revealing that the PSDs are generally fractal. Nevertheless, it should be noted that, unlike other results [21], the NMR is sometimes found unhelpful for calculating the fractal dimension value for large pores in $\mathrm{H} 8$ tight sandstones (initial fractal dimension equal to 3.5077 in this case) and the NMR-derived PSDs could be divided into two parts: self-similar set (fractal dimension equal to 2.9903 in this case) and non-self-similar set with inflection point (71.9686 ms in this case) (Figure 6(b)). Therefore, only the pores which correspond to the self-similar set were summarized and then the modified fractal dimension of the pore structure could be derived from the slope of the best fit line (Figure 6(b)). The characteristics of mineral grains and distributions of interstitial minerals would result in abundant hydrophobic pores without brine, and those void pores might be the reason for the unpredictable fractal dimension value. It will be analyzed subsequently. 


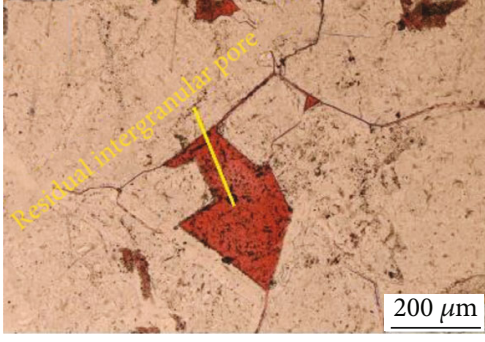

(a)

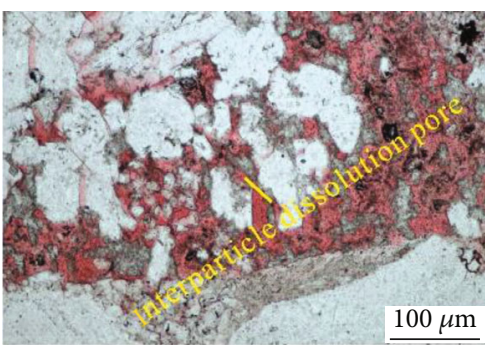

(c)

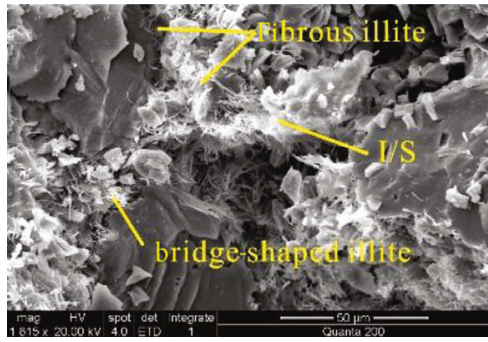

(e)

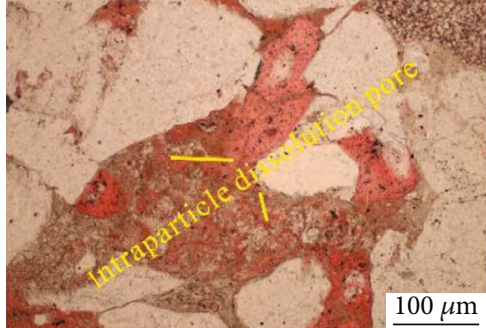

(b)

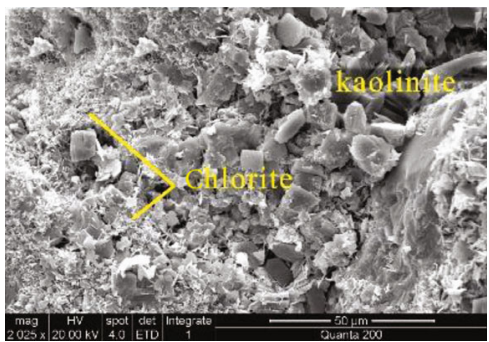

(d)

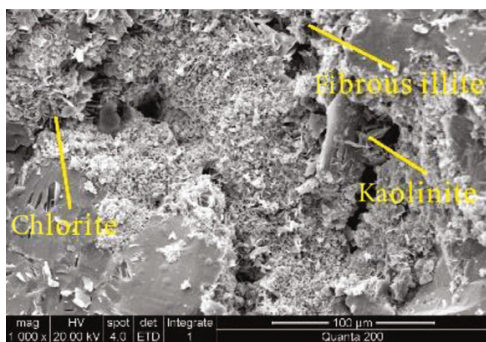

(f)

FIGURE 3: Typical images from the TS and SEM: (a) abundant residual intergranular pores; (b) intraparticle feldspar dissolution pores; (c) interparticle feldspar dissolution pores; (d) the surfaces of the rock particles are covered with rosette-shaped chlorite and the pores are filled with vermicular-shaped kaolinite; (e) the surfaces of the rock particles are covered with the I/S mixed layer, fibrous, and bridgeshaped illite; (f) chlorite, kaolinite, and kaolinite began to develop to shrink pores and throats.

\section{Discussion}

4.1. Pore Structure Classification Based on PCMI-Derived Fractal Dimension Values. The pore system inside the rock is complex and reflects the sedimentation and diagenesis comprehensively; thus, the classifications of pore structures are often roughly identified by a singular test $[55,56]$. Therefore, due to the complexity of pore structures, the data points do not fall on a regression curve in the research area, while they are usually scattered in a banded range [55]. As mentioned above, our work showed that the fractal geometry based on different tests has a significant effect on the pore structure typing; hence, a combination method was chosen to determine the reasonable pore structure classification. PCMI test is one of the most economical methods to reveal the PSD over a broad range of sizes effectively from nanometer to microns [57]; therefore, we gain information from this experiment and perform pore structure characterization first. Type P1 specimens were the most abundant class with double-linear fractal straight regression lines, revealing that this kind of reservoir has a relatively homogeneous pore structure with singular fractal geometry (Figures 4(a) and $4(c))$. The correlation coefficients for petrophysical proper- ties and $D_{P i 1}$ are very limited in type P1 species, suggesting that the fractal theory based on PCMI data points could not reflect the reservoir quality properly (Figure 7), whereas other fractal dimension values have no relationships with porosity and permeability $\left(R^{2}<0.1\right)$. Type $\mathrm{P} 2$ samples with low and ultralow porosity and permeability showed no relationships with $D_{P i 1}$, and the high- $D_{P i 2}$ fractal dimension values suggest that super complex pore structures would lead to the reservoir quality deterioration (Figure 7).

The medium-high correlation coefficient for $D_{P e 1}$ and porosity (presented in the inset figure in Figure $7(\mathrm{a})$ ) provide the evidence of the model proposed by Sakhaee-Pour and Bryant [23], who believe that the tree-like network could mimic the clay-related pores. For the type P1 samples, due to the relatively high porosity and permeability, the clayrelated pores contributed little to the pore network, which correspond to a low hysteresis (from -0.89 to -0.34 in this specimen) (Figure 8(a)). However, for the type P2 samples, the elevation of $D_{P e 1}$ represents the heterogeneity of clayrelated pores and abundant clay minerals could improve the pore space to some extent because the discrepancy between the intergranular pores and the clay-related pores 


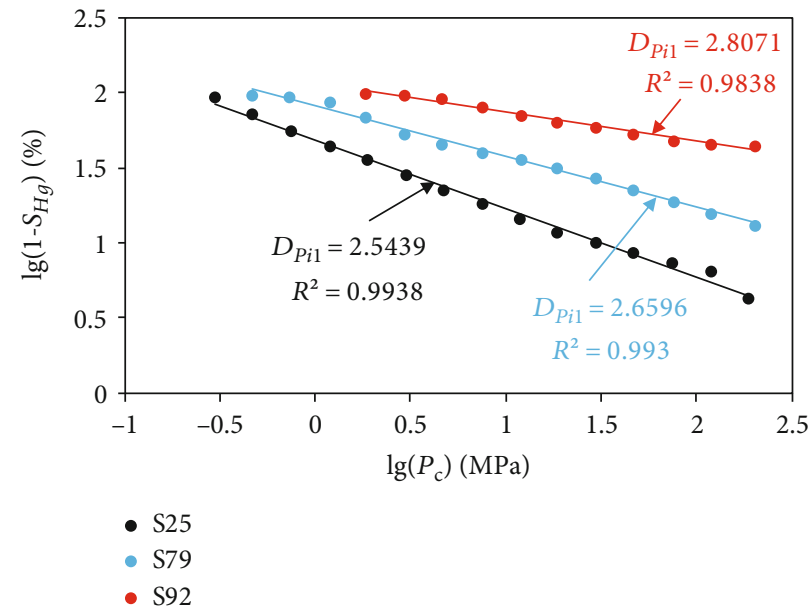

(a)

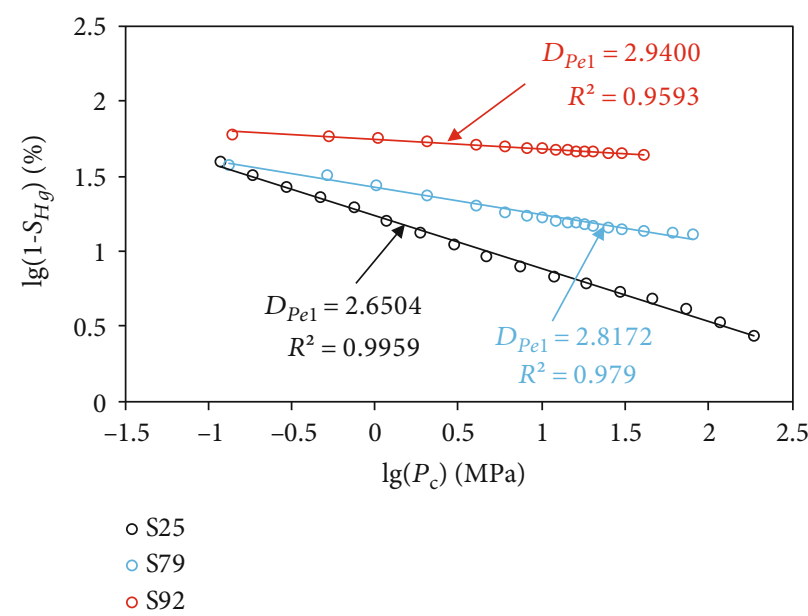

(c)

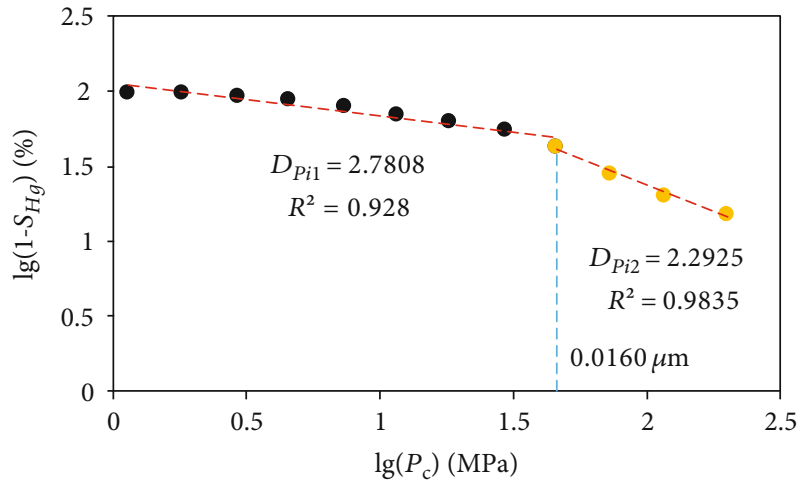

- Large fractal pore set

- Small fractal pore set

(b)

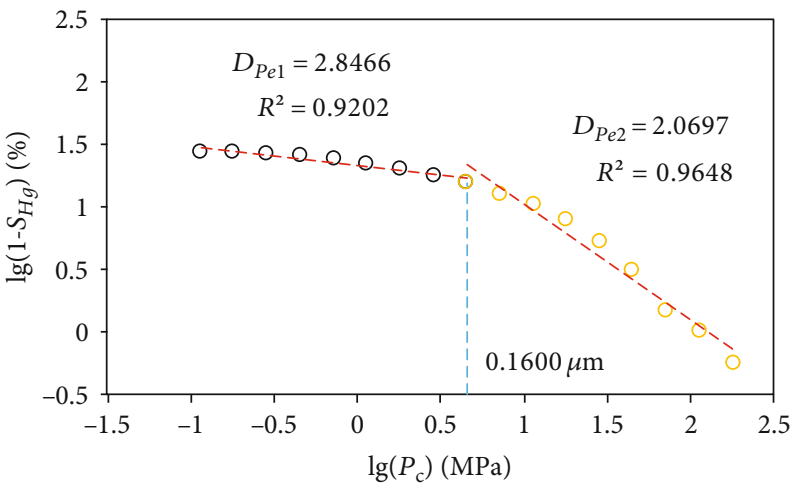

○ Large fractal throat set

- Small fractal throat set

(d)

FIGURE 4: Double logarithmic plots of wetting phase saturation versus capillary pressure from PCMI experiments: type I of (a) intrusion and (c) extrusion branches from three typical specimens; type II of (b) intrusion and (d) extrusion branches from S22 and S95, respectively. $D_{P i 1}$ : fractal dimension values from intrusion branches of PCMI tests or large fractal pore set; $D_{P i 2}$ : small fractal pore set; $D_{P e 1}$ : fractal dimension values from extrusion branches of PCMI tests or large fractal throat set; $D_{P e 2}$ : small fractal throat set.

was diminished, which corresponds to a high hysteresis (from -0.91 to 0.05 in this specimen) (Figure 8(b)). Therefore, the clay-related fractal pore set $\left(D_{P e 1}\right)$ could be a good indicator for the clay-related porosity prediction (inset figure in Figure 7(a)).

There is only one P3 sample in the research area, and this specimen has medium porosity and permeability. In this case, the total difference appearance of the fractal geometry might be resulting from the cracking behavior in the process of experiment due to the high injection pressure, because there are no obvious microcracks in the micrographs and relatively abundant residual intergranular pores and dissolution pores manifest that the sample did not experience strong compaction which would easily lead to fractures (Figure 9(a)). The sharp increase of the nonwetting phase (mercury) with less elevated capillary pressure in mercury intrusion curves and rapid withdraw efficiency in the initial stages of mercury extrusion curves also supported this reasoning (Figure 9(b)), and the outlier $\left(D_{P i 2}=1.7351 \notin(2,3)\right)$ indicates that this part belongs to the non-self-similar set with dual-pore structures characterized by clay-related pores with a tiny radius and microcracks which could make contributions to the industrial hydrocarbon flow [58]. Besides, the inflection points of intrusion and extrusion branches corresponding to the same nonwetting phase saturation basically, that is, the logarithmic nonwetting phase saturation lower than approximately 1.27 which belonged to the spaces of clay and microcracks, demonstrate the existence of artificial microcracks (Figure 9(b)).

4.2. Pore Structure Classification Based on RCMI-Derived Fractal Dimension Values. Like the PCMI-based classification, all the specimens were grouped into six parts based on the RCMI results and the morphology of fractal distributions from throat and pore branches. Based on the fractal throat set, the H8 tight sandstones could be divided into two parts: monofractal throat (Figure 5(a)) and bifractal throat groups 


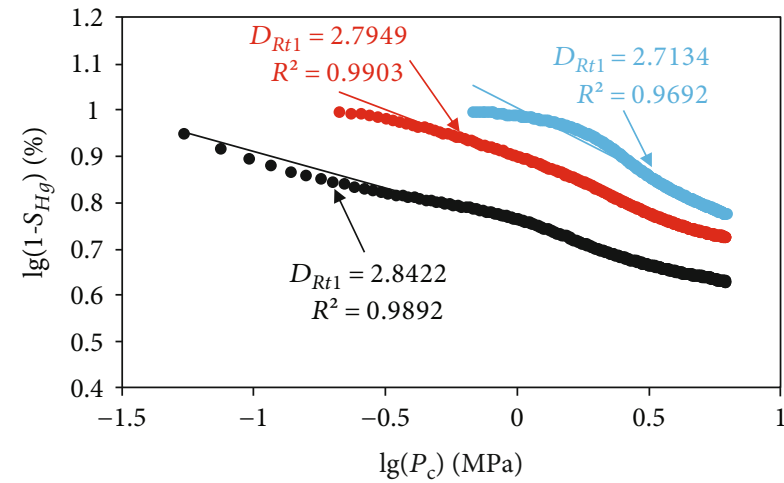

- S25

- $\mathrm{S} 12$

- $\mathrm{S} 10$

(a)

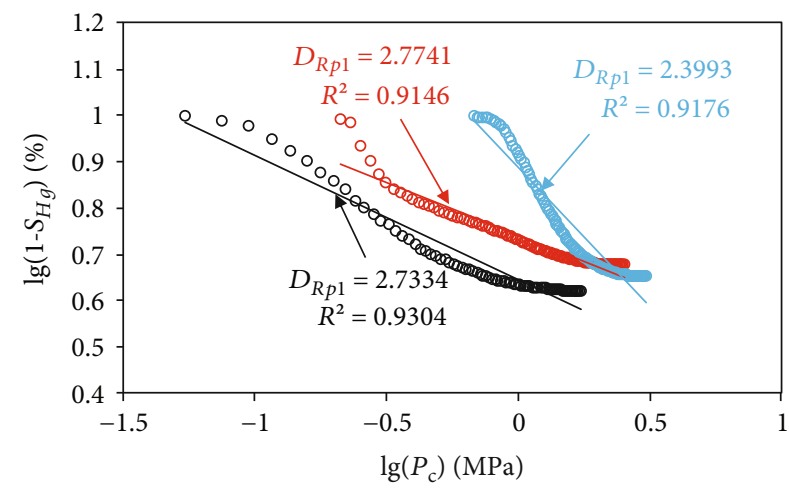

○ S25

- $\mathrm{S} 12$

○ $\mathrm{S} 10$

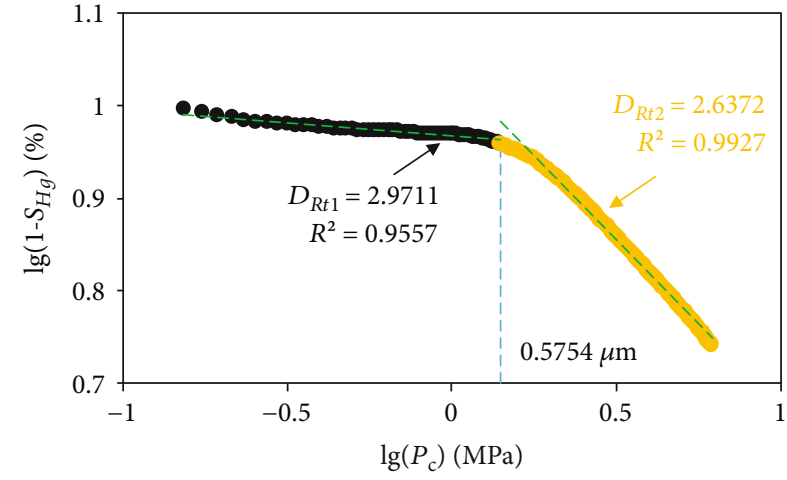

- Large fractal throat set

- Small fractal throat set

(b)

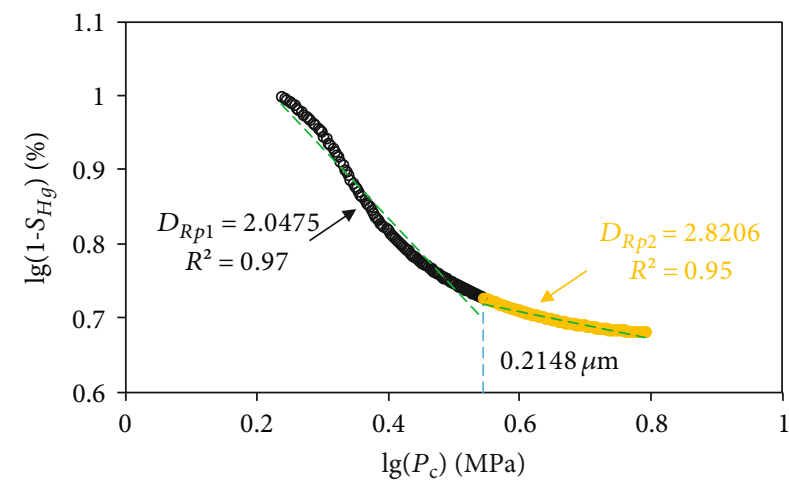

- Large fractal pore set

- Small fractal pore set

(c)

(d)

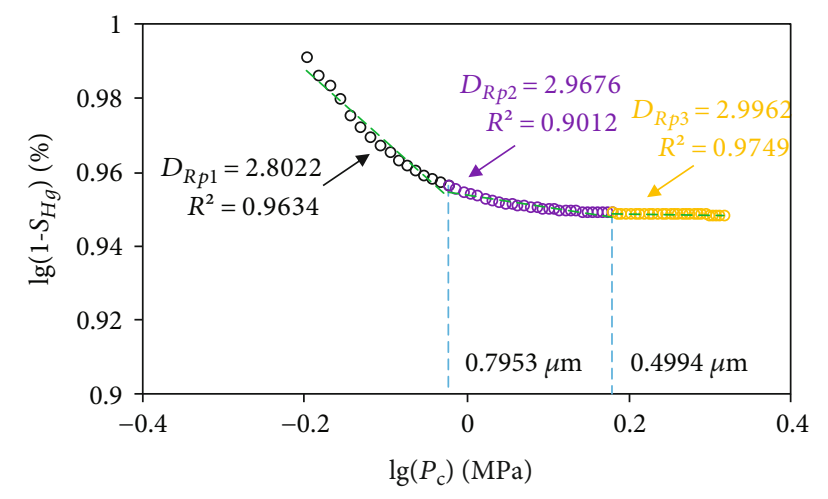

- Large fractal pore set

- Medium fractal pore set

- Small fractal pore set

(e)

FIGURE 5: Double logarithmic plots of wetting phase saturation versus capillary pressure from RCMI experiments: (a) type I of the throat set from three typical specimens; (b) type II of the throat set from S46; (c) type I of the pore set from three typical specimens; types (d) II and (e) III of the pore set from S26 and S78, respectively. $D_{R t 1}$ : fractal dimension values from throat branches of RCMI tests or large fractal throat set; $D_{R t 2}$ : small fractal throat set; $D_{R p 1}$ : fractal dimension values from pore branches of RCMI tests or large fractal pore set; $D_{R p 2}$ : small or medium fractal pore set; $D_{R p 3}$ : small fractal pore set. 


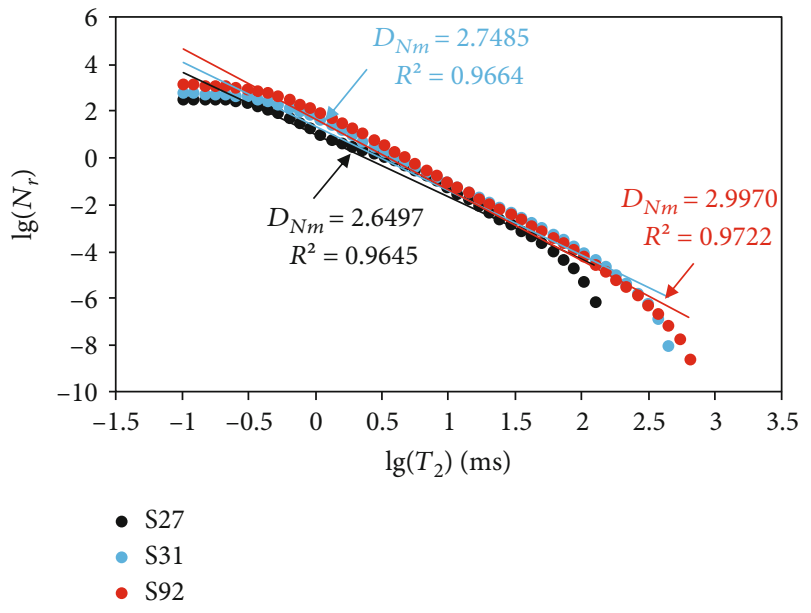

(a)

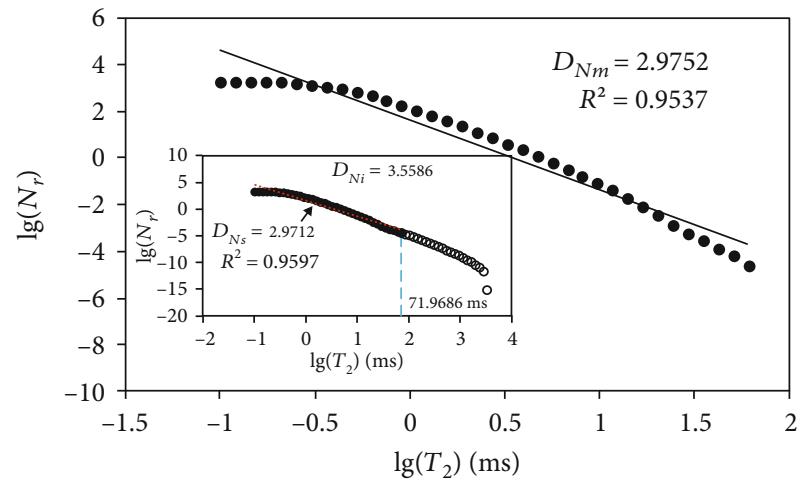

- Self-similar set

- Non-self-similar set

(b)

FIGURE 6: Double-logarithm coordination showing the relationship between the $\lg \left(N_{r}\right)$ and $\lg \left(T_{2}\right)$ for (a) three typical samples and (b) specimen with multiple segments from S46. $D_{N i}$ : initial fractal dimension values; $D_{N s}$ : fractal dimension values of the self-similar set; $D_{N m}$ : modified fractal dimension values; boundary-boundary between self- and non-self-similar sets.

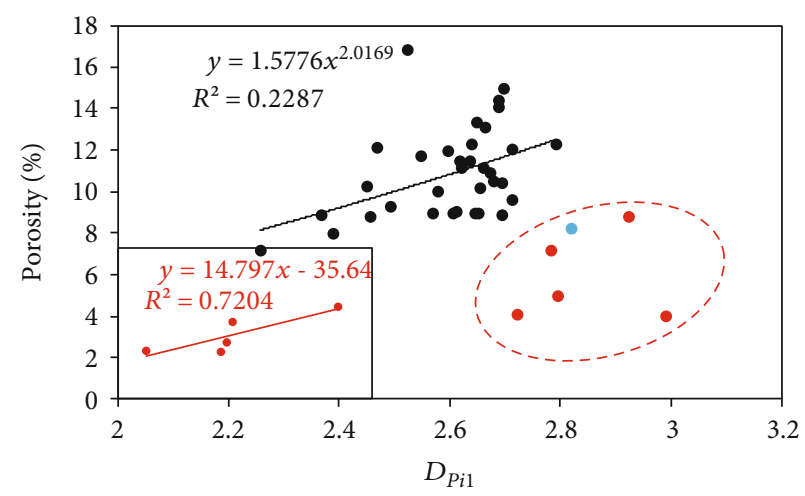

- Type P1

- Type P2

- Type P3

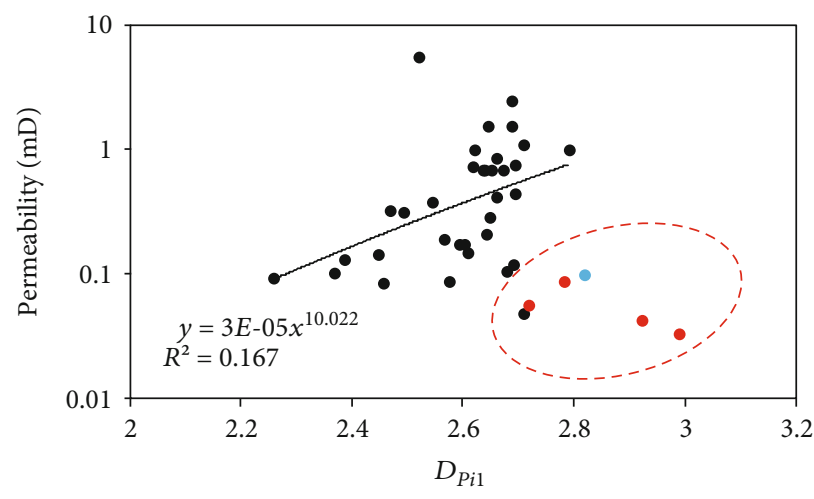

- Type P1

- Type P2

- Type P3

(a)

(b)

FIGURE 7: The cross-plots between multifractal parameters from PCMI tests and petrophysical properties: (a) the cross-plots between $D_{P i 1}$ and porosity (the inset plots presented the relationships between $D_{P e 1}$ and porosity for type P2 sandstones); (b) the cross-plots between $D_{P i 1}$ and permeability.

(Figure 5(b)), and those two groups combined with different pore sets could form six kinds of pore structure typing, namely, R1 to R6. Figure 10 shows that there are distinct boundaries between the monofractal (types R1, R2, and R3) and bifractal throat (types R4, R5, and R6) groups, suggesting that their intrinsic pore-throat networks were entirely different. Based on the relationships between throat-derived fractal dimension values and petrophysical properties for monofractal samples, the porosity and permeability gradually increased with fractal dimension values being increased, whether it is in the type R1, R2, or R3 species (Figures 10(a) and $10(\mathrm{~b})$ ). Those trends could be interpreted that the stronger distributional heterogeneity of throat structures means having abundant large throat and preferential fluid immigration volume. Meanwhile, type R1 specimens also have the highest correlation coefficients for pore-derived fractal dimension values and petrophysical properties, indicating the validity and rationality of the porosity and permeability estimation for Type R1 sandstones (Figures 10(c) and 10(d)). The scattered data points from Figures 10(c) and 10(d) reveal that compared with the pore size distributions, the larger and homogeneous throats is vital for the determination of the reservoir quality, and macro-pores and throats were always the predominant factors on storage and percolation.

Bifractal throat distributions, as shown in Figures 5(b), 10(a), and 10(b), could be an indicator for poor reservoir quality, and the following reasons can account for this phenomenon. In monofractal specimens, punctate throats play a dominant role in the percolation and abundant 


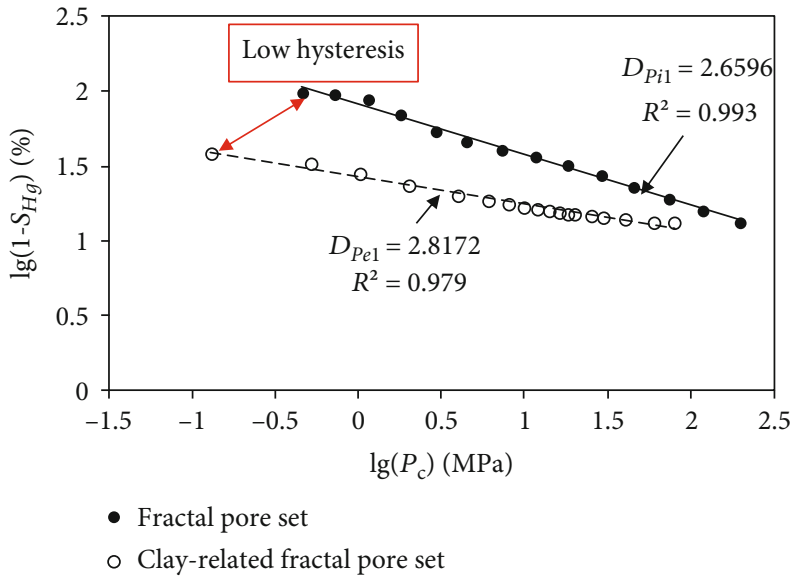

(a)

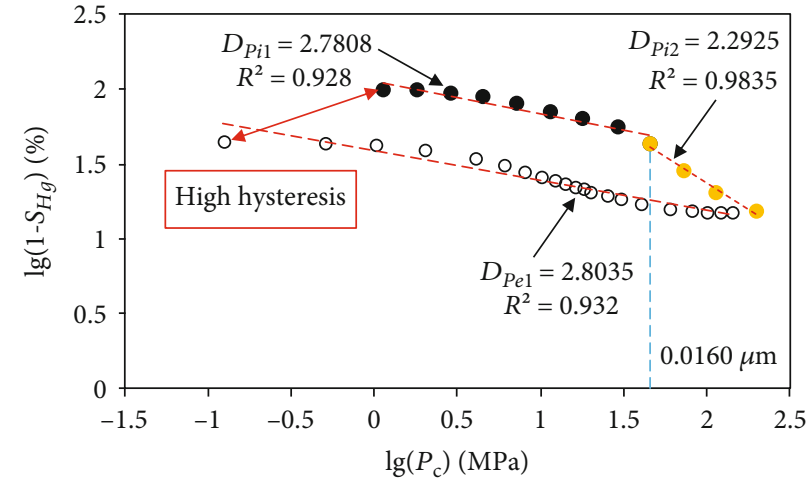

- Large fractal pore set

- Small fractal pore set

- Clay-related fractal pore set

(b)

FIGURE 8: Double logarithmic plots of wetting phase saturation versus capillary pressure from PCMI experiments: (a) type P1 sample from H179; (b) type P2 sample from S22.

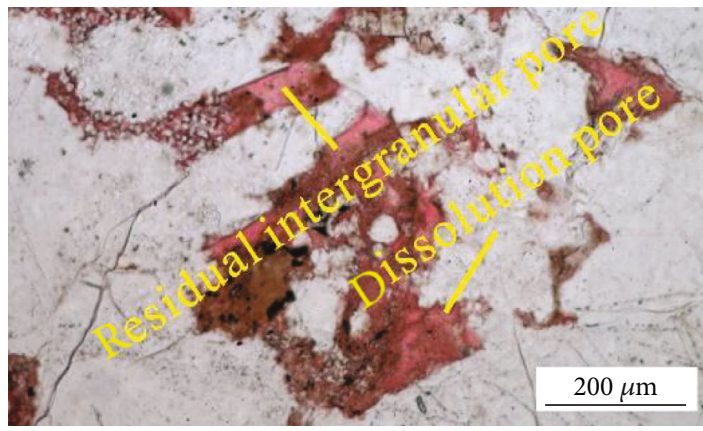

(a)

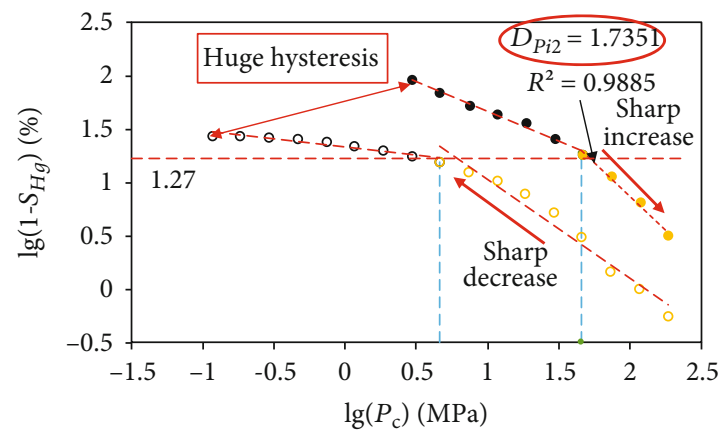

- Large fractal pore set $\circ$ Large fractal throat set

- Small fractal pore set $\circ$ Small fractal throat set

(b)

Figure 9: (a) Optical observation and (b) double logarithmic plots of wetting phase saturation versus capillary pressure from PCMI experiments for the type P3 sample from S95.

punctate throats usually represent mass-distributed residual intergranular pores and weak mechanical compaction corresponding to good reservoir quality; therefore, the throat distributions were relatively simple (Figure 11(a)). Compared with the monofractal samples, the bifractal throat set distributions reveal that the throat networks were complicated and the proportion of laminated throats increased, which were the evidence of strong mechanical compaction (Figure 11(b)) [59]. A combination of various kinds of throats indicates the deteriorated pore structures (Figure 11(b)) and is corresponding to relatively high fractal dimension values (Figures 10(a) and 10(b)). Therefore, once the bifractal throat distributions were observed, we can infer that the corresponding sandstones have very limited pore spaces and poor reservoir quality. Although monofractal pore distributions were usually accompanied by good reservoir qualities (except sample X30 which belongs to type P2), however, it is hard to determine whether the petrophysical properties of bifractal pore dis- tributions are greater than those of trifractal pore distributions (Figures 10(c) and 10(d)). Further investigations need to be done for the purpose of accurate prediction of the reservoir quality.

4.3. Pore Structure Classification Based on NMR-Derived Fractal Dimension Values. As mentioned in Section 3.2.3, there are only two types of NMR-derived fractal distributions in the research area and we defined the specimens with monofractal behavior as N1 sandstones (Figure 6(a)) and those with two parts at the initial stage were N2 sandstones (Figure 6(b)). For type N1 sandstones, there have been relatively low modified fractal dimension values (av. 2.82) while the values for $\mathrm{N} 2$ sandstones were approaching 3.0 (av. 2.90). The cross-plots between $D_{N m}$ and petrophysical properties are shown in Figure 12, and there are nearly no correlations between those parameters, revealing that singular NMR-derived fractal dimension values could not predict 

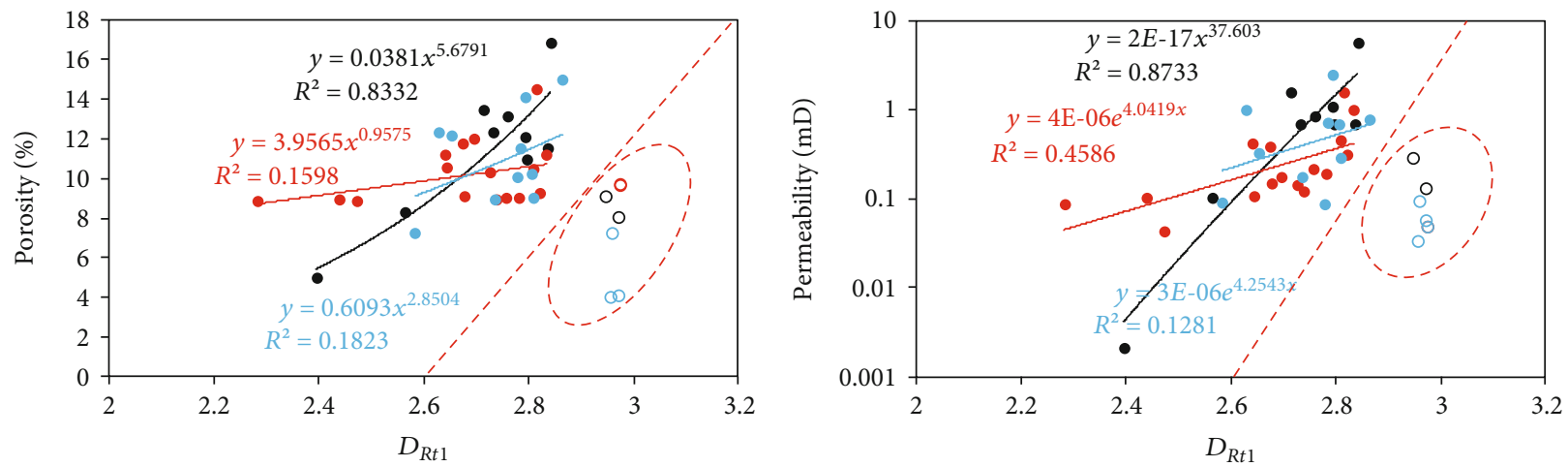

- Type R1 o Type R4

- Type R2 o Type R5

- Type R3 ○ Type R6

(a)

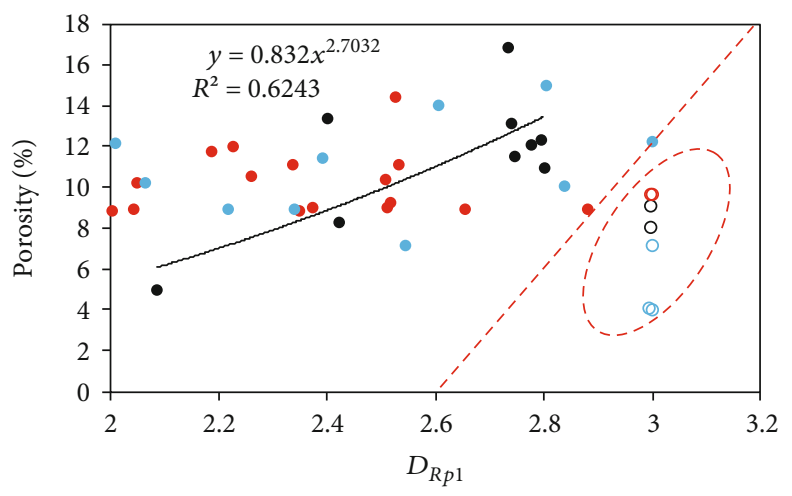

- Type R1 o Type R4

- Type R2 o Type R5

- Type R3 ○ Type R6

(b)

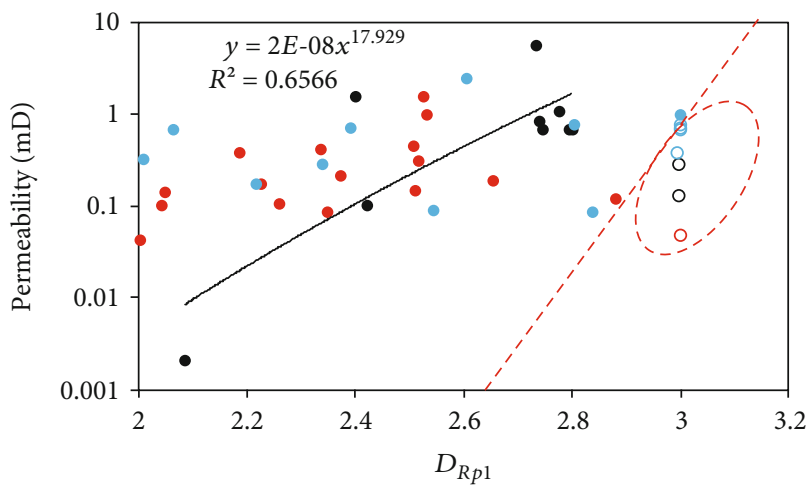

- Type R1 o Type R4

- Type R1 o Type R4

- Type R2 o Type R5

- Type R2 O Type R5

- Type R3 ○ Type R6

(c)

(d)

FIGURE 10: The cross-plots between multifractal parameters from RCMI tests and petrophysical properties: (a) the cross-plots between $D_{R t 1}$ and porosity; (b) the cross-plots between $D_{R t 1}$ and permeability; (c) the cross-plots between $D_{R p 1}$ and porosity; (d) the cross-plots between $D_{R p 1}$ and permeability.

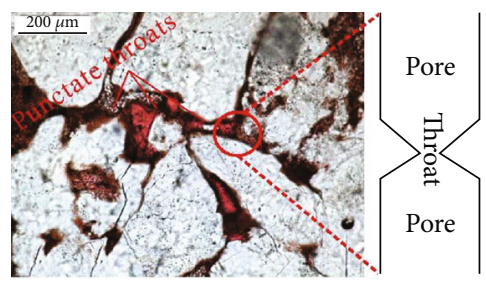

(a)

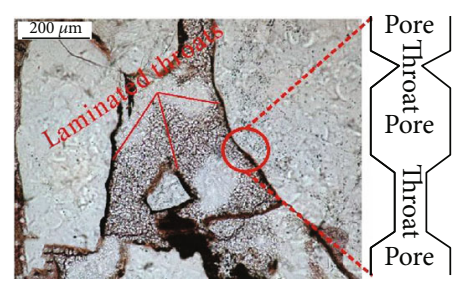

(b)

FIGURE 11: Optical observation and pore-throat combination: (a) monofractal throat distribution specimen (from type R1, S26); (b) bifractal throat distribution specimen (from type R4, S65).

petrophysical properties effectively; further research needs to be done combined with the preceding conclusions.

In general, high fractal dimension values correspond to complex pore structures with poor reservoir quality; however, in the $\mathrm{H} 8$ sandstones, $\mathrm{N} 2$ specimens have relatively high porosity and permeability (av. $10.75 \%$ and av. $0.80 \mathrm{mD}$, respectively) compared with $\mathrm{N} 1$ samples with low petrophy- sical properties (av. 9.53\% and av. $0.32 \mathrm{mD}$, respectively). Figure 13 demonstrates the brine charging before the NMR tests: (a) for the illite-rich specimen (type N1); due to abundant hydrophilic illite [60], the brine can get access to the most of the pores, revealing a complete picture of the pore network in the $T_{2}$ spectrum; (b) for the samples that chlorite covered the majority of the pore surfaces (type N2), some 


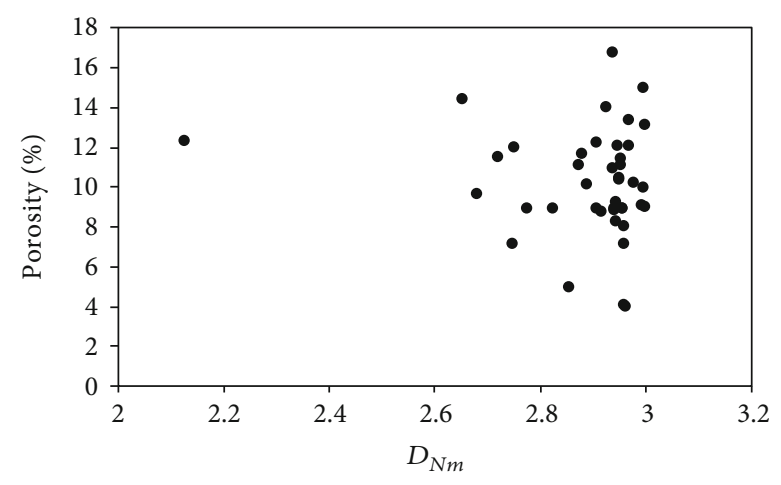

(a)

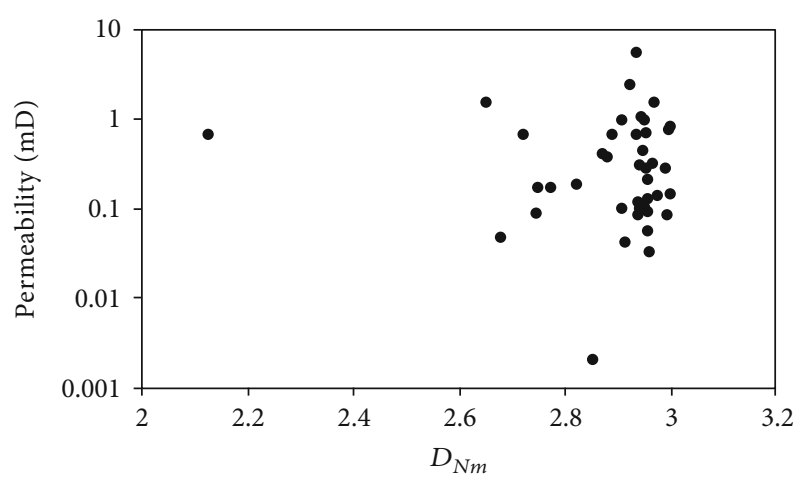

(b)

Figure 12: The cross-plots between modified fractal parameters from NMR tests and petrophysical properties: (a) the cross-plots between $D_{N m}$ and porosity; (b) the cross-plots between $D_{N m}$ and permeability.

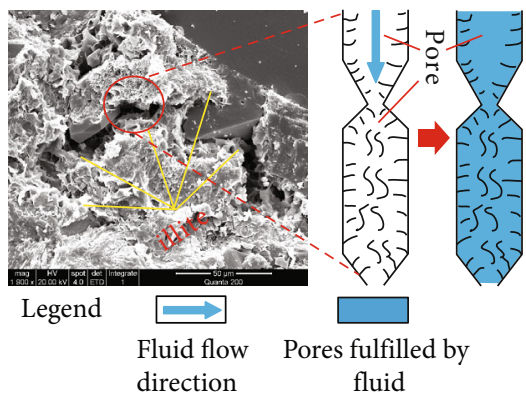

(a)

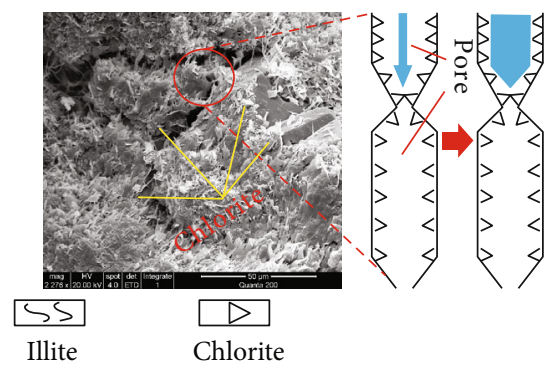

(b)

FIGURE 13: SEM imaging and schematic diagrams of the brine charging process. (a) Type N1 sandstone from S65; (b) type N2 sandstone from S24.

pores have almost no brine that resulted from the hydrophobic chlorite [61]. Therefore, the wettability lead to the heterogeneous distributions of brine in type N2 sandstones, which caused a non-self-similar set from NMR tests for all the data points, and they need to be modified (Section 3.2.3). The reasons for high petrophysical properties in type $\mathrm{N} 2$ sandstones were the positive role of chlorite in pore network protection [62]. Hence, the main function of NMR-derived fractal dimension values in $\mathrm{H} 8$ tight sandstones was to determine the absolute contents of hydrophilic and hydrophobic clay minerals.

4.4. Effective Pore Structure Typing Based on Microscopic Observations and Multifractal Distributions. Because of the complexity of pore networks in H8 tight sandstones, only a deep understanding of the petrology and pore structures can accurately estimate the storage ability and percolation capacity of the internal pore volume. Thus, a multiscale analysis from qualitative observations to quantitative tests, from intrusion methods (PCMI and RCMI) to nonintrusion experiment (NMR), can allow us to fully understand the internal discrepancy of pore networks and the distinction between different pore structure typing and a new criterion is proposed to predict the reservoir quality based on microscopic observations and multifractal distributions.
As mentioned above, based on the results of intrusion methods, type P2, P3, R4, R5, and R6 sandstones do not have the qualification to become an effective reservoir, because the type P2 sandstones have very poor reservoir qualities, whereas type $\mathrm{P} 3$ specimens were induced by the microcracks during the PCMI tests (Figures 8 and 9) and the intensive diagenesis of type R4, R5, and R6 sandstones leads to the low porosity and permeability (Figures 10 and 11). Therefore, three types of pore structures with two subclasses for each type are identified by the multifractal distributions. Six typical specimens from each pore structure typing were selected for the study (Figure 14), and the corresponding results are summarized in Table 1. As shown in Figures 14(a) and 14(b), the main difference between the pore structure typing of the intrusion methods is the RCMI-derived fractal distributions, because the PCMIderived fractal distributions shared similar trends. In the P1R1 type, a gentle increase of nonwetting phases based on pore and throat branches with double-monofractal distribution was observed. These indicate that the pore-throat structures were relatively homogeneous. In the P1R2 type, a bifractal distribution developed and the large fractal pore sets have relatively small fractal dimension values while the small fractal pore set shows a negligible increase of nonwetting phases corresponding to the large fractal dimension values. This phenomenon illustrates a heterogeneous pore network 

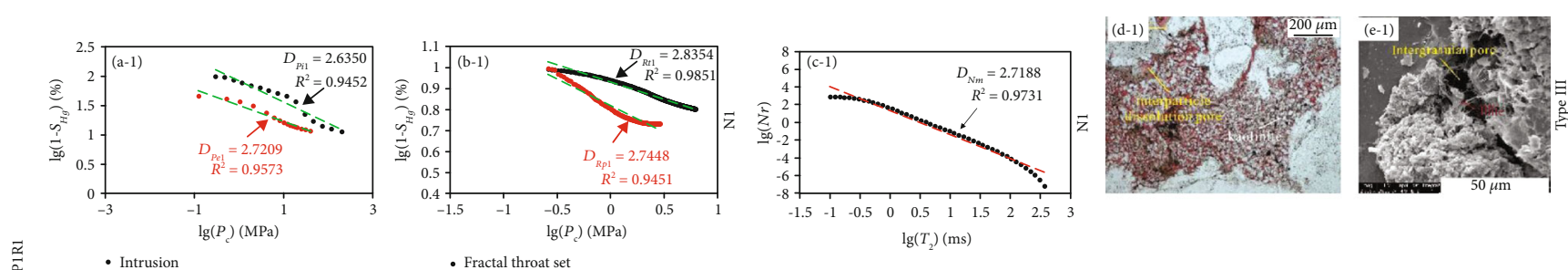

$$
\begin{aligned}
& \text { - Fractal throat set } \\
& \text { - Fractal pore set }
\end{aligned}
$$
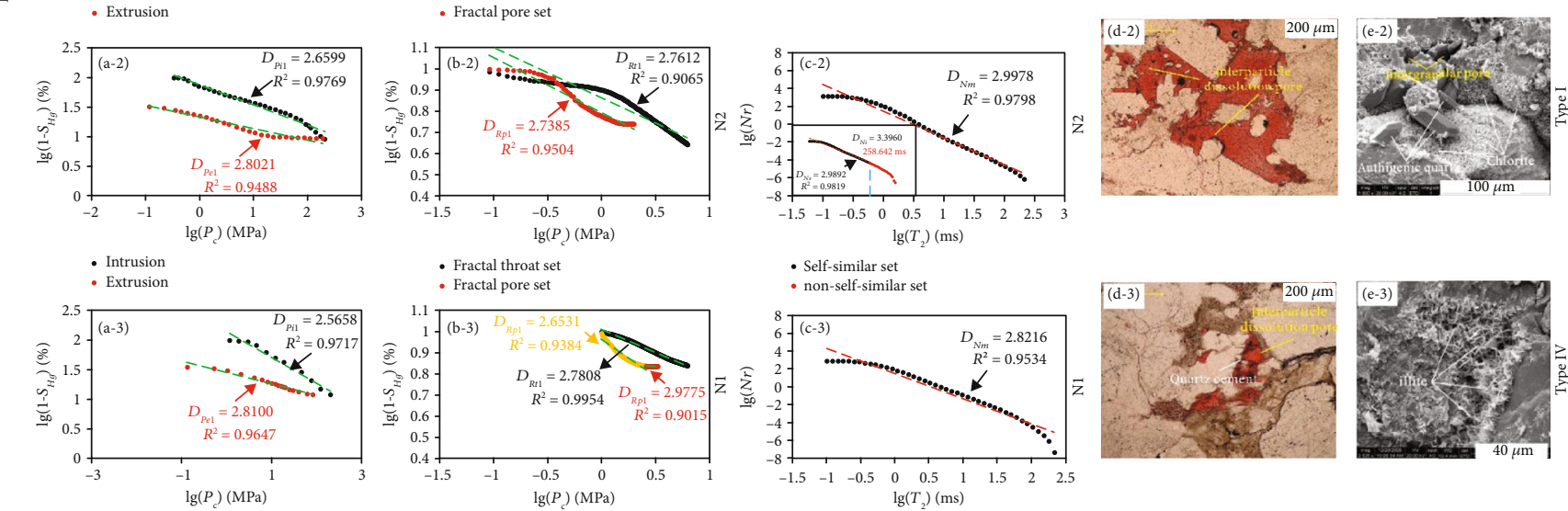

- Self-similar set

- non-self-similar set

$\approx \quad$ : Intrusion

- Fractal throat set
- Large fractal pore set

- Small fractal pore set
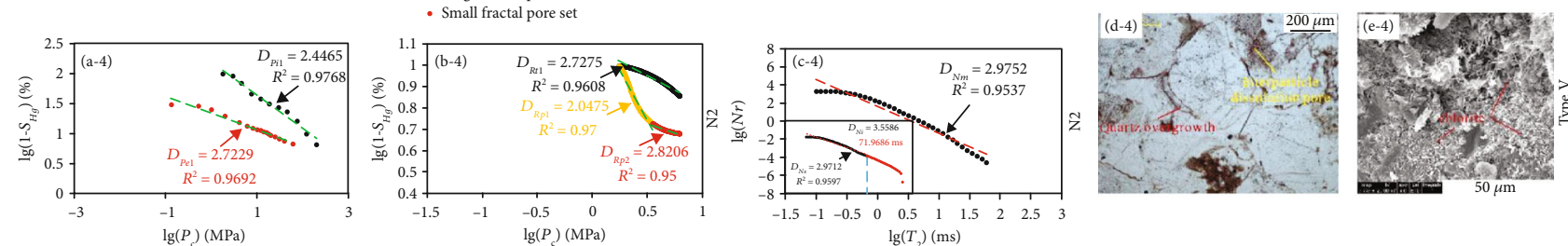

- Intrusio

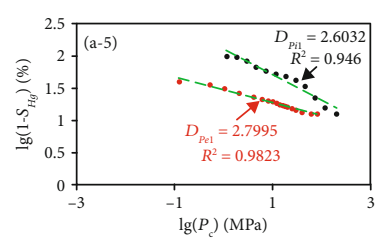

- Fractal throat set

- Fractal throat set
- Large fractal pore set - Small fractal pore set

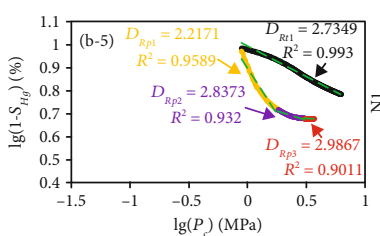
- non-self-similar set
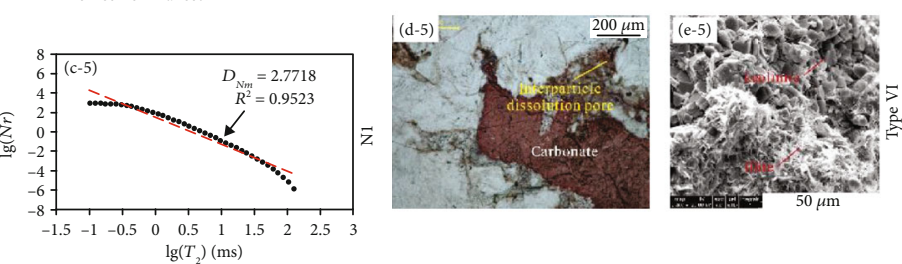

$\begin{array}{ll}2 & \text { - Intrusion } \\ 2 & \text { Extrusion }\end{array}$

- Fractal throat set

- Large fractal pore set

- Medium fractal pore set

- Small fractal pore set.
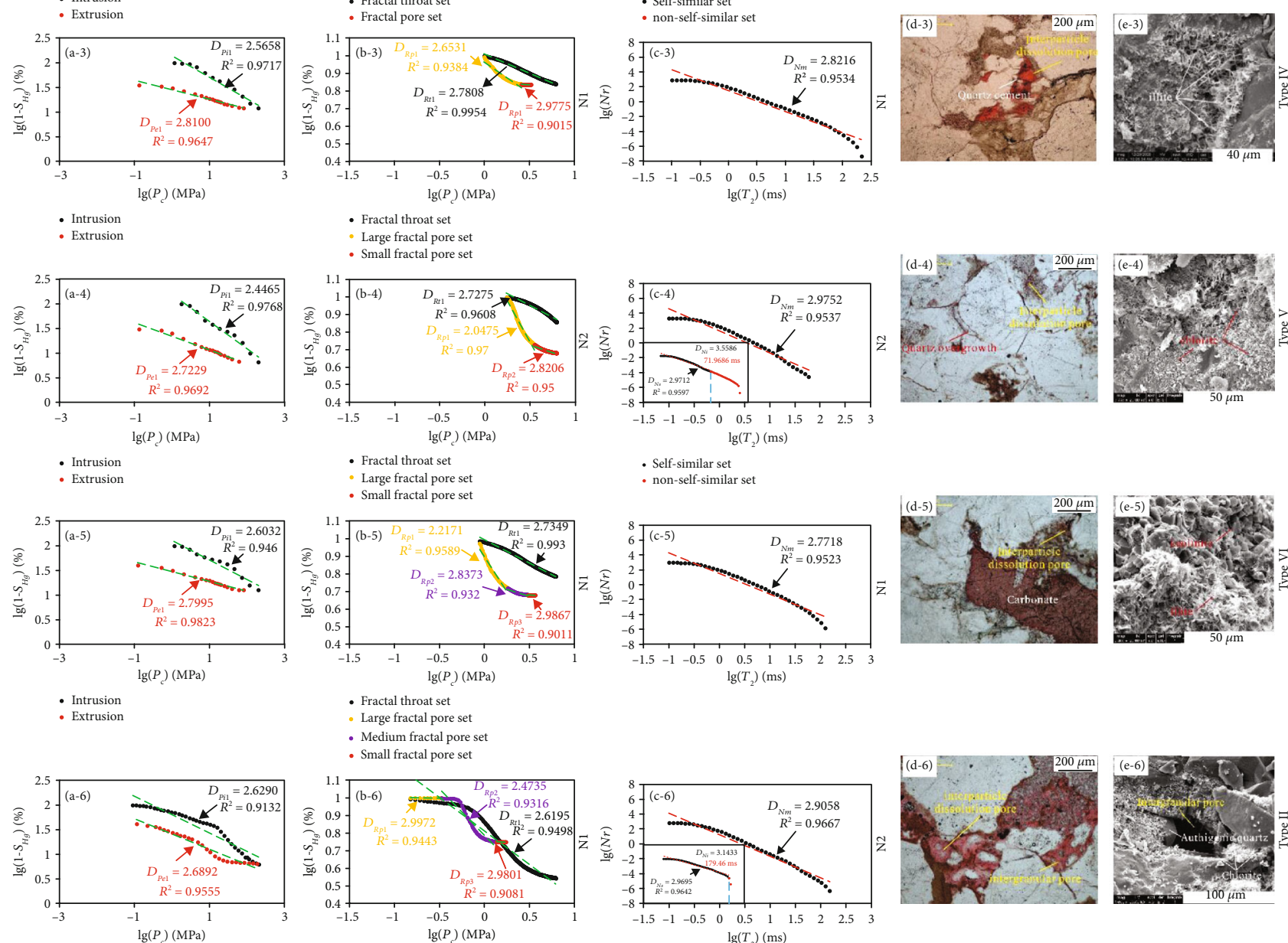

- Intrusion

- Fractal throat set

- Large fractal pore set

- Medium fractal pore se

- Self-similar set

- Small fractal pore set

FIgURE 14: (a) Multifractal distributions proposed by PCMI tests; (b) multifractal distributions proposed by RCMI tests; (c) fractal distributions proposed by NMR tests; (d) TS for pore geometry and mineralogical analysis; (e) SEM images for mineral features. Typical specimen of type I from S29, type II from S27, type III from S39, type IV from S47, type V from S26, and type VI from S18.

with large pores and fine throats. In the figures of P1R3, trifractal distributions in the RCMI-derived pore curve resulted from the complex pore structures indicating that various kinds of pores are distributed in tight sandstones.

Each group could be divided into two subtypes based on the NMR results (Figure 14(c)). As previously mentioned, the difference between the N1 and N2 types was the clay mineral assembly. TS and SEM provide good insight into the pore structures and mineralogical recognition (Figures 14(d) and 14(e)). For all the main categories, type N1 tight sandstones have relatively abundant illite, while the chlorites play a dominant role in the N2 tight sandstones. Chlorite could warp the 
TABLE 1: Petrological and petrophysical property characteristics based on the statistical average from type I to type VI of H8 tight sandstones.

\begin{tabular}{|c|c|c|c|c|c|c|c|c|}
\hline \multirow{2}{*}{ Type } & \multirow{2}{*}{ Porosity (\%) } & \multirow{2}{*}{ Permeability (\%) } & \multicolumn{4}{|c|}{ Absolute content of clay (\%) } & \multirow{2}{*}{ Sample quantities } & \multirow{2}{*}{ Fractal assembly } \\
\hline & & & Illite & Chlorite & $\mathrm{I} / \mathrm{S}$ & Kaolinite & & \\
\hline $\mathrm{I}$ & 13.30 & 1.96 & 0.50 & 2.66 & 0.56 & 2.05 & 5 & P1R1N2 \\
\hline II & 12.01 & 0.81 & 1.90 & 1.84 & 0.41 & 1.46 & 7 & P1R3N2 \\
\hline III & 10.98 & 0.51 & 5.51 & 0.69 & 0.70 & 1.33 & 3 & P1R1N1 \\
\hline IV & 10.30 & 0.39 & 1.23 & 2.37 & 0.53 & 0.67 & 6 & P1R2N1 \\
\hline $\mathrm{V}$ & 10.27 & 0.33 & 1.83 & 1.85 & 0.65 & 1.31 & 9 & P1R2N2 \\
\hline VI & 9.39 & 0.38 & 3.07 & 1.90 & 1.55 & 3.00 & 2 & P1R3N1 \\
\hline
\end{tabular}

detrital grains and resisted the mechanical compaction, or they would clog the pore-throat system directly, while illite fulfilled the void spaces and deteriorated the storage and percolation directly; therefore, type N1 sandstones generally have greater reservoir quality than type N2 (Table 1). Besides, the products of the dissolution are precipitated into interstitial minerals, such as carbonate (ferrocalcite and ankerite), quartz cement, and clay, which would also block the pores and narrow the throats, and have a very limited contribution to the improvement of the petrophysical properties, especially the intraparticle dissolution pores [55]. The intergranular pores generated by relatively large grains could enhance the storage and percolation capacity.

To sum up, six types of pore structures with effective storage and percolation capacity were concluded. From Figure 14, type I sandstones correspond to P1R1N2 multifractal distributions; all pores are generally homogeneous and are composed by intergranular pores and partly intergranular pores (Figure 14(d-2)). Lamellar chlorites do not clog the pores and throats and only few illites were observed; slight authigenic quartz resists the mechanical compaction to some extent, obviously (Figure 14(e-2)). The pore and throat branches nearly paralleled to each other with low hysteresis (Figure 14(b-2)). This pore structure typing has the highest porosity and permeability in the research area (Table 1). Compared with type I, the pore structures of type II correspond to the P1R3N2 fractal distributions and have relatively poor reservoir quality (Table 1 ). This type shows two kinds of chlorite with different functions; the sheet chlorites wrapped around the detrital grains to resist further compaction $[24,63]$, while some petaloid chlorites block the pores directly (Figure 14(e-6)). Additionally, more carbonates have precipitated, further reducing the pore space and making complex the pore geometry, resulting in the trifractal distributions in RCMI-derived pore curves also with low hysteresis (Figures 14(b-6) and 14(d-6)). P1R1N1 corresponds to type III sandstones, although they have relatively homogenous pore structures; abundant illite and ferrocalcite are the main reasons for the decrease in reservoir quality (Figures 14(d-1) and 14(e-1) and Table 1). Improved hysteresis of pore and throat branches is another significant evidence of low storage and percolation ability (Figure 14(b-1)). In type IV sandstones (P1R2N1), although sheet chlorite and quartz overgrowth wrapped the pores and preserve few intergranular pores (Figure 14(d-3)), mass-distributed illite deteriorated the petrophysical properties seriously (Figure 14(e-3) and Table 1). The transfer capacity of type V (P1R2N2) was predominantly determined by the intragranular pores and the dissolution of columnar feldspar (Figures 14(d-4) and $14(\mathrm{e}-4))$. Intensive mechanical compaction is the main reason for the decrease in reservoir quality, which leads to pressure dissolution (Table 1) [64]. The boundary between type $\mathrm{V}$ and type VI (P1R3N1) tight sandstones is vague if we referred to the porosity and permeability (Table 1). The pore network is determined by intergranular pores and concomitantly by intraparticle dissolution pores in type VI tight sandstone, and filiform illite plays the most dominant role in the clay minerals (Figures 14(d-5) and 14(e-5)). The RCMIderived fractal dimension values share similar trends in types $\mathrm{V}$ and VI, compared with type II tight sandstones, in which the large fractal pore sets have very low fractal dimension values. Due to the inhomogeneous pore structures in those types, high fractal dimension values of large pores generally represent the existence of very large pores with very good storage and percolation capacity, while relatively low values indicate that the large pores in those types are homogenously distributed with a small radius. These might be the main reasons for the poorest effective reservoir quality in type $\mathrm{V}$ and VI tight sandstones.

4.5. Reservoir Quality Prediction Based on Fractal Dimension Values. When the pore structure typing of all data points and the relationships between multifractal dimension values and petrophysical properties have been determined, the reservoir quality, defined here as the amounts of porosity and permeability, could be estimated based on our methods. As mentioned above, only $D_{R t 1}$ has distinct relationships with reservoir quality (Figures $10(\mathrm{a})$ and $10(\mathrm{~b})$ ). Although there is an obvious positive correlation between $D_{P e 1}$ and porosity for type P2 sandstones, we shall not discuss that here, because this type of sandstones could not be the effective reservoir with commercial hydrocarbon flow (Figure $7(\mathrm{a})$ ). The results for six typical specimens are presented in Figures 15(a) and 15(b), and the reservoir quality can be estimated by fitting the empirical formula from this research:

$$
\begin{array}{r}
\varphi=0.0114 D_{R t 1}{ }^{6.9918,} \\
K=6 \times 10^{-20} D_{R t 1}^{43.959},
\end{array}
$$

where $\varphi$ and $K$ represent porosity and permeability, respectively. Therefore, the reservoir quality was calculated by equations (18) and (19) and the measured porosity and permeability were conducted by the experiments. The result 


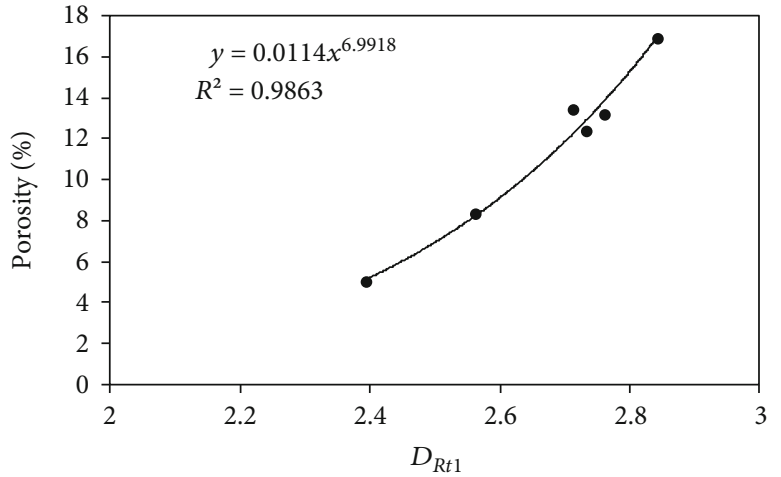

(a)

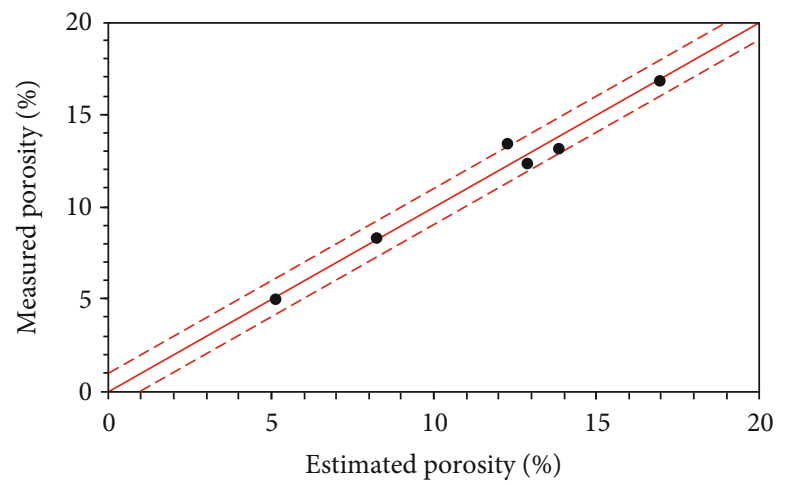

(c)

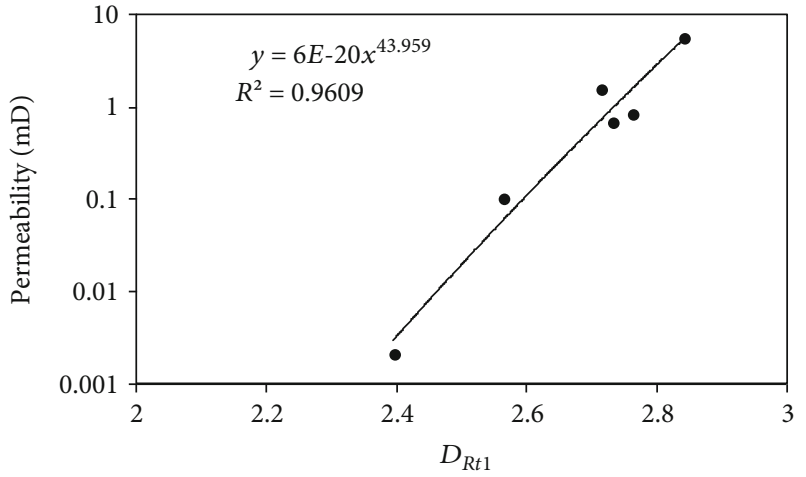

(b)

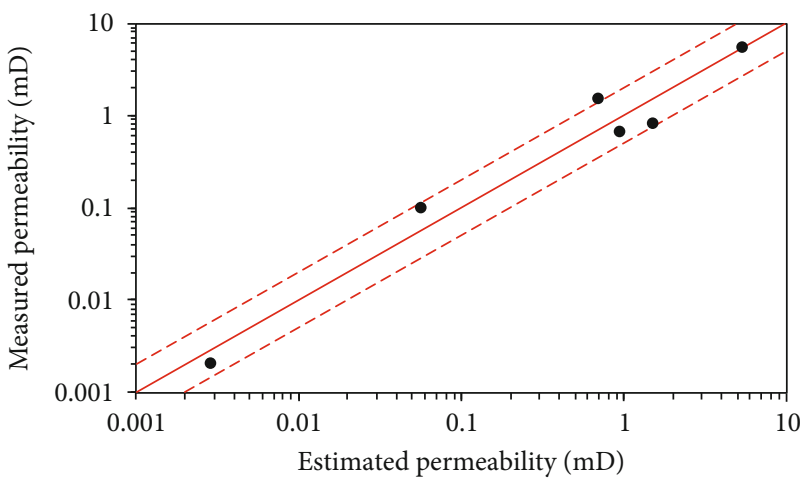

(d)

Figure 15: Plot of $D_{R t 1}$ versus (a) porosity and (b) permeability from six typical specimens. Comparison between estimated and measured (c) porosity and (d) permeability for six typical specimens by equations (18) and (19).

shows that the estimated porosity nearly falls around the $1: 1$ standard line with an error of within 5\% (Figure 15(c)), revealing the rationality of equation (18); however, there is a sharp difference between estimated and measured permeabilities with an error of over 30\% (Figure 15(d)), indicating the invalidity of equation (19). This comparison reveals that rationality of the porosity prediction based on fractal theory may not have valid permeability estimation and this formula prediction is accurate only based on good petrophysical properties and not suitable for poor reservoir quality sandstones. Hence, much more work will need to be done to untangle how fractal theories contribute to reservoir quality prediction.

\section{Conclusions}

In this study, the multifractal distributions of the $\mathrm{H} 8$ tight sandstones in the Ordos Basin, China, were studied to characterize the pore structure heterogeneity and a more sophisticated and accurate criterion was presented to determine the pore structure typing. The following conclusions were obtained:

(1) The pore structure typing of the tight sandstones of the research area based on multifractal distributions derived from PCMI, RCMI, and NMR can be classified into three, six, and two types, respectively. Type $\mathrm{P} 1, \mathrm{R} 1, \mathrm{R} 2$, and R3 sandstones indicate the most effective reservoir with relatively high petrophysical properties. Type N1 tight sandstones have relatively ample hydrophilic clay assemblage, while type N2 specimens were abundant with hydrophobic clay minerals

(2) A comprehensive analysis of petrology and pore structures by multifractal distributions derived from different tests were conducted, and a new criterion was proposed. Based on this, six effective pore structure types with different mineral compositions, porethroat structures, and multifractal dimension values were identified in the research area

(3) The throats of tight sandstones control the reservoir quality predominantly compared with other parameters. $D_{R t 1}$ exhibits perfect performance in the estimation of the porosity (error factor less than 10\%). Deeper multifractal analysis needs to be done in order to enhance insight into the pore structures and reservoir quality prediction in tight sandstones

\section{Data Availability}

The thin section and SEM images are provided by the State Key Laboratory of Continental Dynamics at the Northwest University in China. The XRD, PCMI, RCMI, and NMR data used for this study are from the State Engineering Laboratory 
for Exploration and Development of Low permeability Oil and Gas Fields in China.

\section{Conflicts of Interest}

The authors declare no conflict of interest.

\section{Authors' Contributions}

Conceptualization was done by Dazhong Ren; data curation was done by Dazhong Ren, Na Liu, and Fu Yang; formal analysis was done by $\mathrm{Na}$ Liu; funding acquisition was done by Dazhong Ren; investigation was done by Rongxi Li and Dengke Liu; methodology was prepared by Rongxi Li and Dengke Liu; project administration was done by Yuhong Li; supervision was done by Rongxi Li and Yuhong Li; writing of the original draft was done by Dazhong Ren; reviewing and editing of the writing were done by Rongxi $\mathrm{Li}$ and Dengke Liu.

\section{Acknowledgments}

This research was cofunded by the Open Fund of State Key Laboratory of Oil and Gas Reservoir Geology and Exploitation (Chengdu University of Technology), grant number: PLC20190502; the Opening Foundation of State Key Laboratory of Continental Dynamics, Northwest University, grant number: 18LCD01; the China Postdoctoral Science Foundation, grant number 2018M643554; the Open Fund of Key Laboratory of Coal Resources Exploration and Comprehensive Utilization, Ministry of Land and Resources, grant numbers: KF2019-1 and ZP2018-2; the Young Science and Technology Talents Foundation of Shaanxi Province, grant number: 2019KJXX-054; and the National Science and Technology Major Project of China, Key Technology of the Tight Gas Enrichment Law and the Exploration and Development, grant number: 2016ZX05047; National Natural Science Foundation of China, grant numbers: 41702146 and 51874242 .

\section{References}

[1] C. Guo, J. Xu, M. Wei, and R. Jiang, "Experimental study and numerical simulation of hydraulic fracturing tight sandstone reservoirs," Fuel, vol. 159, pp. 334-344, 2015.

[2] Z. Jiang, Z. Mao, Y. Shi, and D. Wang, "Multifractal characteristics and classification of tight sandstone reservoirs: a case study from the Triassic Yanchang Formation, Ordos Basin, China," Energies, vol. 11, no. 9, p. 2242, 2018.

[3] G. Desbois, J. L. Urai, P. A. Kukla, J. Konstanty, and C. Baerle, "High-resolution 3D fabric and porosity model in a tight gas sandstone reservoir: a new approach to investigate microstructures from $\mathrm{mm}$ - to $\mathrm{nm}$-scale combining argon beam cross-sectioning and SEM imaging," Journal of Petroleum Science and Engineering, vol. 78, no. 2, pp. 243257, 2011.

[4] J. Lai, G. Wang, Z. Fan, Z. Zhou, J. Chen, and S. Wang, "Fractal analysis of tight shaly sandstones using nuclear magnetic reso- nance measurements," AAPG Bulletin, vol. 102, no. 2, pp. 175$193,2018$.

[5] J. Xiong, X. Liu, and L. Liang, "Experimental study on the pore structure characteristics of the Upper Ordovician Wufeng Formation shale in the southwest portion of the Sichuan Basin, China," Journal of Natural Gas Science and Engineering, vol. 22, pp. 530-539, 2015.

[6] H. Wang, Y. Liu, Y. Song, Y. Zhao, J. Zhao, and D. Wang, "Fractal analysis and its impact factors on pore structure of artificial cores based on the images obtained using magnetic resonance imaging," Journal of Applied Geophysics, vol. 86, pp. 70-81, 2012.

[7] K. E. Higgs, H. Zwingmann, A. G. Reyes, and R. H. Funnell, "Diagenesis, porosity evolution, and petroleum emplacement in tight gas reservoirs, Taranaki Basin, New Zealand," Journal of Sedimentary Research, vol. 77, no. 12, pp. 1003-1025, 2007.

[8] S. Sun, L. Shu, Y. Zeng, J. Cao, and Z. Feng, "Porosity-permeability and textural heterogeneity of reservoir sandstones from the Lower Cretaceous Putaohua Member of Yaojia Formation, Weixing Oilfield, Songliao Basin, northeast China," Marine and Petroleum Geology, vol. 24, no. 2, pp. 109-127, 2007.

[9] P. H. Nelson, "Pore-throat sizes in sandstones, tight sandstones, and shales," AAPG Bulletin, vol. 93, no. 3, pp. 329340, 2009.

[10] Z. Zhang and A. Weller, "Fractal dimension of pore-space geometry of an Eocene sandstone formation," Geophysics, vol. 79, no. 6, pp. D377-D387, 2014.

[11] H. Daigle, A. Johnson, and B. Thomas, "Determining fractal dimension from nuclear magnetic resonance data in rocks with internal magnetic field gradients," Geophysics, vol. 79, no. 6, pp. D425-D431, 2014.

[12] J. Lai and G. Wang, "Fractal analysis of tight gas sandstones using high-pressure mercury intrusion techniques," Journal of Natural Gas Science and Engineering, vol. 24, pp. 185-196, 2015.

[13] J. Xiong, X. Liu, and L. Liang, "An investigation of fractal characteristics of marine shales in the Southern China from nitrogen adsorption data," Journal of Chemistry, vol. 2015, Article ID 303164, 12 pages, 2015.

[14] Q. Hu, R. P. Ewing, and S. Dultz, "Low pore connectivity in natural rock," Journal of Contaminant Hydrology, vol. 133, pp. 76-83, 2012.

[15] A. J. Katz and A. H. Thompson, "Fractal sandstone pores: implications for conductivity and pore formation," Physical Review Letters, vol. 54, no. 12, pp. 1325-1328, 1985.

[16] H. Bu, Y. Ju, J. Tan, G. Wang, and X. Li, "Fractal characteristics of pores in non-marine shales from the Huainan Coalfield, eastern China," Journal of Natural Gas Science and Engineering, vol. 24, pp. 166-177, 2015.

[17] X. Liu, J. Xiong, and L. Liang, "Investigation of pore structure and fractal characteristics of organic-rich Yanchang Formation shale in central China by nitrogen adsorption/desorption analysis," Journal of Natural Gas Science and Engineering, vol. 22, pp. 62-72, 2015.

[18] S.-Y. Xu and S.-P. Wang, "Fractal feature about the microstructure in sandstone reservoir: taking the Paleogene Shahejie Formation in Shengtuo Oilfield as an example," Natural Gas Geoscience, vol. 24, no. 5, pp. 886-893, 2013.

[19] A. Sakhaee-Pour and W. Li, "Fractal dimensions of shale," Journal of Natural Gas Science and Engineering, vol. 30, pp. 578-582, 2016. 
[20] H. Huang, L. Chen, W. Sun et al., "Pore-throat structure and fractal characteristics of Shihezi Formation tight gas sandstone in the Ordos Basin, China," Fractals, vol. 26, no. 2, article 1840005, 2018.

[21] F. Zhu, W. Hu, J. Cao, F. Sun, Y. Liu, and Z. Sun, “Micro/Nanoscale Pore Structure and Fractal Characteristics of Tight Gas Sandstone: A Case Study from the Yuanba Area, Northeast Sichuan Basin, China," Marine and Petroleum Geology, vol. 98, pp. 116-132, 2018.

[22] R. Rezaee, A. Saeedi, and B. Clennell, "Tight gas sands permeability estimation from mercury injection capillary pressure and nuclear magnetic resonance data," Journal of Petroleum Science and Engineering, vol. 88-89, pp. 92-99, 2012.

[23] A. Sakhaee-Pour and S. L. Bryant, "Effect of pore structure on the producibility of tight-gas sandstones," AAPG Bulletin, vol. 98, no. 4, pp. 663-694, 2014.

[24] D. Xiao, S. Jiang, D. Thul, S. Lu, L. Zhang, and B. Li, "Impacts of clay on pore structure, storage and percolation of tight sandstones from the Songliao Basin, China: implications for genetic classification of tight sandstone reservoirs," Fuel, vol. 211, pp. 390-404, 2018.

[25] H. H. Yuan and B. F. Swanson, "Resolving pore-space characteristics by rate-controlled porosimetry," SPE Formation Evaluation, vol. 4, no. 1, pp. 17-24, 1989.

[26] W. Huang, S. Lu, O. S. Hersi, M. Wang, S. Deng, and R. Lu, "Reservoir spaces in tight sandstones: classification, fractal characters, and heterogeneity," Journal of Natural Gas Science and Engineering, vol. 46, pp. 80-92, 2017.

[27] H. Huang, W. Sun, W. Ji et al., "Effects of pore-throat structure on gas permeability in the tight sandstone reservoirs of the Upper Triassic Yanchang Formation in the Western Ordos Basin, China," Journal of Petroleum Science and Engineering, vol. 162, pp. 602-616, 2018.

[28] G. H. Sørland, K. Djurhuus, H. C. Widerøe, J. R. Lien, and A. Skauge, "Absolute Pore Size Distributions from NMR," Diffusion Fundamentals, vol. 5, pp. 4.1-4.15, 2007.

[29] X. Dong, J. Sun, J. Li, H. Gao, X. Liu, and J. Wang, "Experimental research of gas shale electrical properties by NMR and the combination of imbibition and drainage," Journal of Geophysics and Engineering, vol. 12, no. 4, pp. 610-619, 2015.

[30] A. Anees, W. Shi, U. Ashraf, and Q. Xu, "Channel identification using 3D seismic attributes and well logging in lower Shihezi Formation of Hangjinqi area, northern Ordos Basin, China," Journal of Applied Geophysics, vol. 163, pp. 139-150, 2019.

[31] D. Liu, W. Sun, D. Ren, and C. Li, "Quartz cement origins and impact on storage performance in Permian Upper Shihezi Formation tight sandstone reservoirs in the northern Ordos Basin, China," Journal of Petroleum Science and Engineering, vol. 178, pp. 485-496, 2019.

[32] Chinese Petroleum Industry Standard, SY/T 6385-2016, the Porosity and Permeability Measurement of Core in Net Confining Stress, National Energy Administration, 2016.

[33] Chinese Petroleum Industry Standard, SY/T 5368-2007, Thin Section Examination of Rock, National Energy Administration, 2007.

[34] Chinese Petroleum Industry Standard, SY/T 5162-2014, Analytical Method of Rock Sample by Scanning Electron Microscope, National Energy Administration, 2014.

[35] Chinese Petroleum Industry Standard, SY/T 5163-2010, Analysis method for clay minerals and ordinary non-clay minerals in sedimentary rocks bythe X-ray diffraction, National Energy Administration, 2010.

[36] Y. Q. Song, L. Venkataramanan, M. D. Hürlimann, M. Flaum, P. Frulla, and C. Straley, " $T_{1}-T_{2}$ correlation spectra obtained using a fast two-dimensional Laplace inversion," Journal of Magnetic Resonance, vol. 154, no. 2, pp. 261-268, 2002.

[37] Chinese Petroleum Industry Standard, SY/T 6490-2014, Specification for Measurement of Rock NMR Parameter in Laboratory, National Energy Administration, 2014.

[38] E. W. Washburn, “The dynamics of capillary flow," Physical Review, vol. 17, no. 3, pp. 273-283, 1921.

[39] W. R. Purcell, "Capillary pressures - their measurement using mercury and the calculation of permeability therefrom," Journal of Petroleum Technology, vol. 1, no. 2, pp. 39-48, 1949.

[40] S. T.-P. a. N. G. I. S. o. P. R. China, Rock capillary pressure measurement, National Energy Administration, 2005.

[41] P. Li, M. Zheng, H. Bi, S. Wu, and X. Wang, "Pore throat structure and fractal characteristics of tight oil sandstone: a case study in the Ordos Basin, China," Journal of Petroleum Science and Engineering, vol. 149, pp. 665-674, 2017.

[42] A. Giri, S. Tarafdar, P. Gouze, and T. Dutta, "Fractal pore structure of sedimentary rocks: simulation in 2-d using a relaxed bidisperse ballistic deposition model," Journal of Applied Geophysics, vol. 87, pp. 40-45, 2012.

[43] B. B. Mandelbrot, D. E. Passoja, and A. J. Paullay, "Fractal character of fracture surfaces of metals," Nature, vol. 308, no. 5961, pp. 721-722, 1984.

[44] J. Bouma, A. Jongerius, O. Boersma, A. Jager, and D. Schoonderbeek, "The function of different types of macropores during saturated flow through four swelling soil horizons 1," Soil Science Society of America Journal, vol. 41, no. 5, pp. 945-950, 1977.

[45] K. Li and R. N. Horne, "Fractal modeling of capillary pressure curves for the geysers rocks," Geothermics, vol. 35, no. 2, pp. 198-207, 2006.

[46] Z. Yuan and P.-C. Liu, "A new capillary pressure model using fractal geometry for coal porous media," Science Technology and Engineering, vol. 15, no. 9, pp. 63-67, 2015.

[47] M. Schmitt, C. P. Fernandes, J. A. B. da Cunha Neto, F. G. Wolf, and V. S. S. dos Santos, "Characterization of pore systems in seal rocks using nitrogen gas adsorption combined with mercury injection capillary pressure techniques," Marine and Petroleum Geology, vol. 39, no. 1, pp. 138-149, 2013.

[48] R. F. Sigal, "Pore-size distributions for organic-shale-reservoir rocks from nuclear-magnetic-resonance spectra combined with adsorption measurements," SPE Journal, vol. 20, no. 4, pp. 824-830, 2015.

[49] H. Daigle and A. Johnson, "Combining mercury intrusion and nuclear magnetic resonance measurements using percolation theory," Transport in Porous Media, vol. 111, no. 3, pp. 669679, 2016.

[50] M. Meng, H. Ge, W. Ji, and X. Wang, "Research on the autoremoval mechanism of shale aqueous phase trapping using low field nuclear magnetic resonance technique," Journal of Petroleum Science and Engineering, vol. 137, pp. 63-73, 2016.

[51] A. Dillinger and L. Esteban, "Experimental Evaluation of Reservoir Quality in Mesozoic Formations of the Perth Basin (Western Australia) by Using a Laboratory Low Field Nuclear Magnetic Resonance," Marine and Petroleum Geology, vol. 57, pp. $455-469,2014$. 
[52] Z. Lianbo and L. Xiang-Yang, "Fractures in sandstone reservoirs with ultra-low permeability: a case study of the Upper Triassic Yanchang Formation in the Ordos Basin, China," AAPG Bulletin, vol. 93, no. 4, pp. 461-477, 2009.

[53] W. E. Galloway, "Deposition and diagenetic alteration of sandstone in northeast Pacific arc-related basins: implications for graywacke genesis," Geological Society of America Bulletin, vol. 85, no. 3, pp. 379-390, 1974.

[54] G. Zhu, L. Gu, J. Su et al., "Sedimentary association of alternated mudstones and tight sandstones in China's oil and gas bearing basins and its natural gas accumulation," Journal of Asian Earth Sciences, vol. 50, pp. 88-104, 2012.

[55] X. Chen, G. Yao, E. Herrero-Bervera et al., "A New Model of Pore Structure Typing Based on Fractal Geometry," Marine and Petroleum Geology, vol. 98, pp. 291-305, 2018.

[56] Z. Song, G. Liu, W. Yang, H. Zou, M. Sun, and X. Wang, "Multi-Fractal Distribution Analysis for Pore Structure Characterization of Tight Sandstone-A Case Study of the Upper Paleozoic Tight Formations in the Longdong District, Ordos Basin," Marine and Petroleum Geology, vol. 92, pp. 842-854, 2018.

[57] Z. M. Sun, X. C. Lu, X. C. Jia, Y. S. Bai, and W. X. Hu, "Optimization of mercury intrusion capillary pressure measurement for characterizing the pore structure of tight rocks," Journal of Nanoscience and Nanotechnology, vol. 17, no. 9, pp. 62426251, 2017.

[58] S. Crampin, "Geological and industrial implications of extensive-dilatancy anisotropy," Nature, vol. 328, no. 6130, pp. 491-496, 1987.

[59] X. Dianshi, L. Shuangfang, L. Zhengyuan, H. Wenbiao, and G. Meiwei, "Combining nuclear magnetic resonance and rate-controlled porosimetry to probe the pore-throat structure of tight sandstones," Petroleum Exploration and Development, vol. 43, no. 6, pp. 1049-1059, 2016.

[60] A. Saada, B. Siffert, and E. Papirer, "Comparison of the hydrophilicity/hydrophobicity of illites and kaolinites," Journal of Colloid and Interface Science, vol. 174, no. 1, pp. 185-190, 1995.

[61] D. Fornasiero and J. Ralston, "Cu (II) and Ni (II) activation in the flotation of quartz, lizardite and chlorite," International Journal of Mineral Processing, vol. 76, no. 1-2, pp. 75-81, 2005.

[62] G. Chen, G. Du, G. Zhang, Q. Wang, C. Lv, and J. Chen, "Chlorite cement and its effect on the reservoir quality of sandstones from the Panyu low-uplift, Pearl River Mouth Basin," Petroleum Science, vol. 8, no. 2, pp. 143-150, 2011.

[63] S. Zhu, X. Wang, Y. Qin et al., "Occurrence and origin of porelining chlorite and its effectiveness on preserving porosity in sandstone of the middle Yanchang Formation in the southwest Ordos Basin," Applied Clay Science, vol. 148, pp. 25-38, 2017.

[64] D. Li and X. Jiang, "Diagenesis and high quality reservoir forecast of the Qingshankou sandstones in the southern Songliao Basin of northeast China," Petroleum Science and Technology, vol. 32, no. 17, pp. 2038-2048, 2014. 

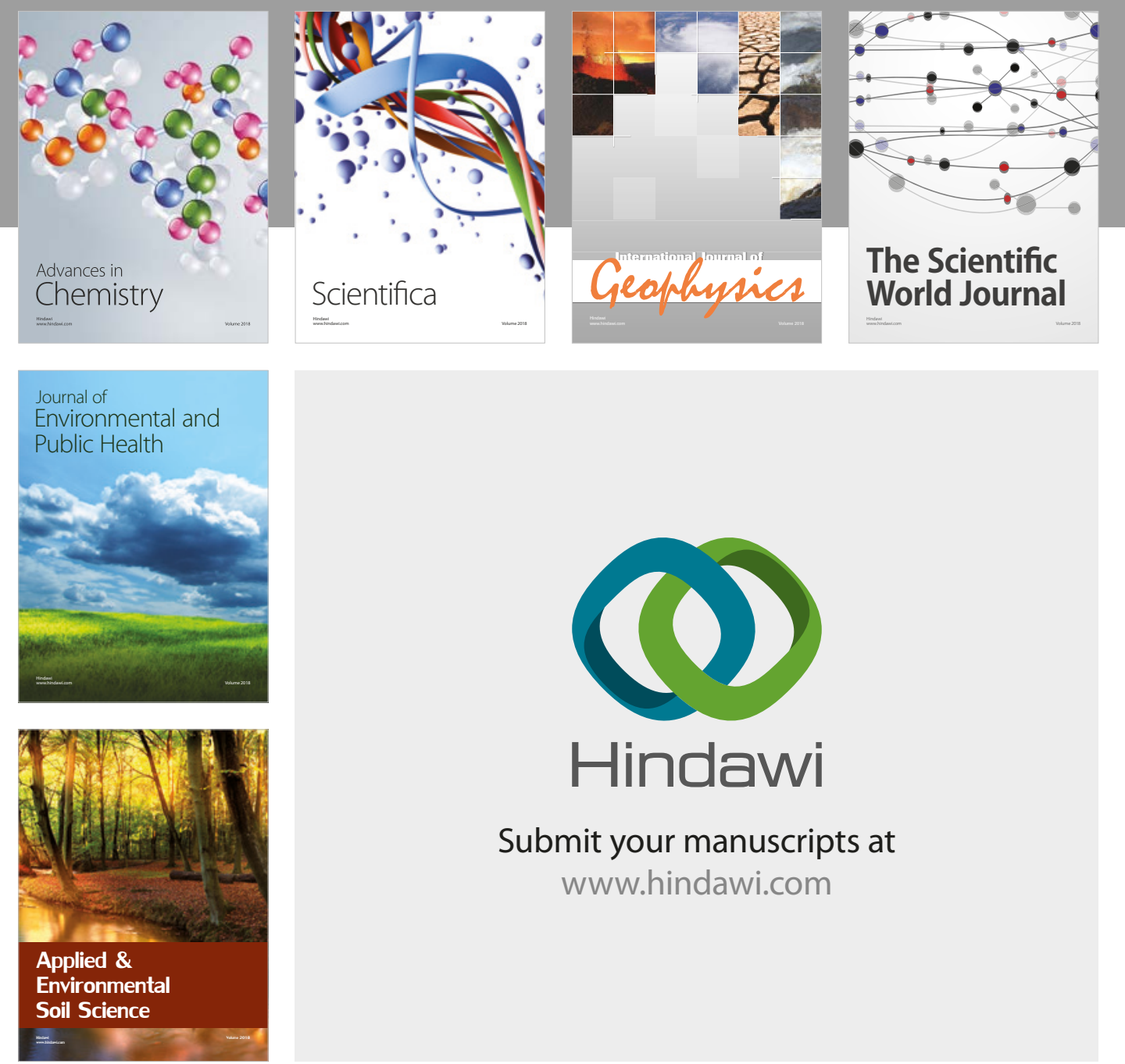

The Scientific

\section{World Journal}
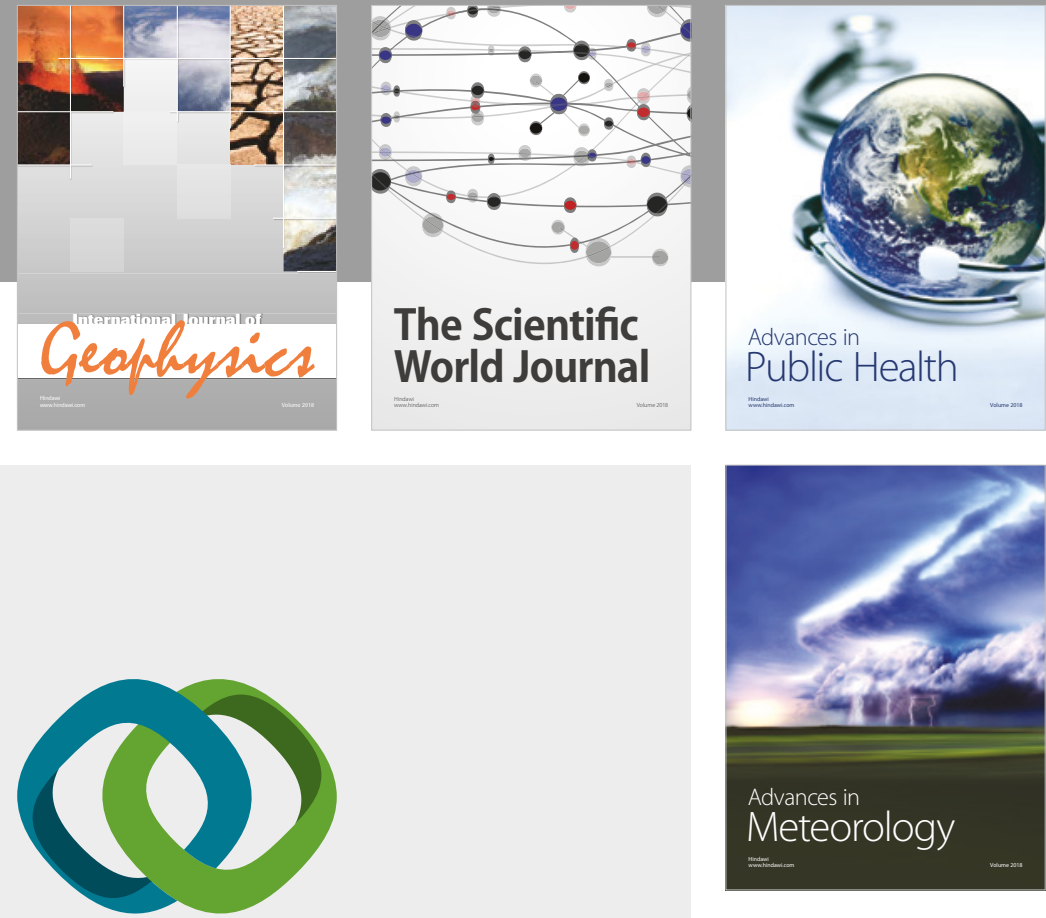

Advan

Public Health

\section{Hindawi}

Submit your manuscripts at

www.hindawi.com
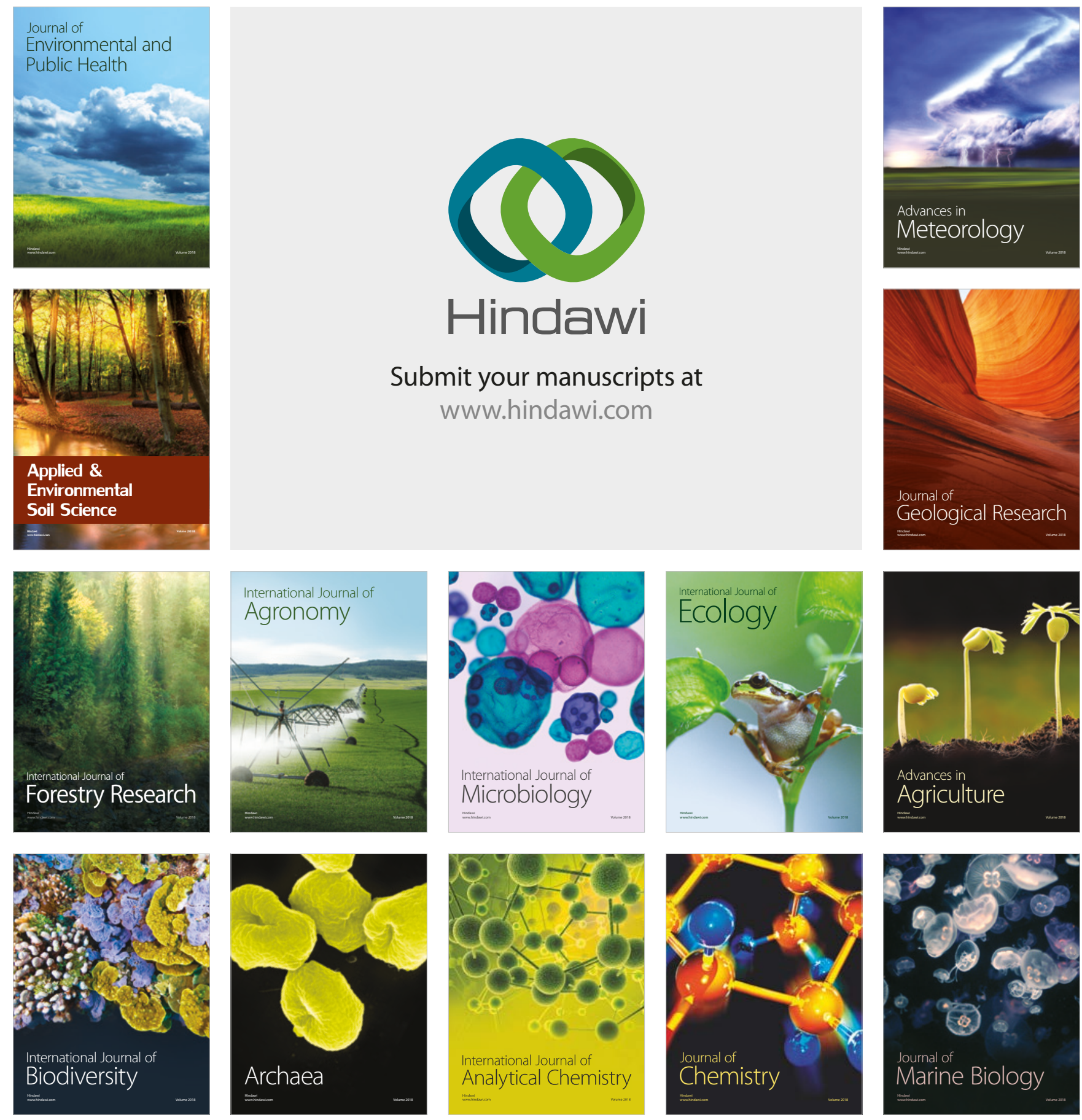